O. Gil-Castell, J. D. Badia, T. Kittikorn, E. Strömberg, A. Martínez-Felipe, M. Ek, S. Karlsson, A. Ribes-Greus.

Hydrothermal ageing of polylactide/sisal biocomposites. Studies of water absorption behavior and physicochemical performance. Polymer Degradation and Stability 2014; 108, 212-222

\title{
HYDROTHERMAL AGEING OF POLYLACTIDE/SISAL BIOCOMPOSITES. STUDIES OF WATER ABSORPTION BEHAVIOUR AND PHYSICO-CHEMICAL PERFORMANCE
}

\section{O. Gil-Castell ${ }^{1}$, J. D. Badia ${ }^{1,2}$, T. Kittikorn ${ }^{3,4}$, E. Strömberg ${ }^{3}$, A. Martínez-Felipe ${ }^{1,5}$, M. Ek ${ }^{3}$, S. Karlsson ${ }^{3,6}$, A. Ribes-Greus ${ }^{1, *}$.}

This is an open-access version, according to http://www.sherpa.ac.uk/romeo/issn/0141-3910/

Full text available at http://www.sciencedirect.com/science/article/pii/S014139101400247X

DOI: doi:10.1016/j.polymdegradstab.2014.06.010

Please, cite it as:

O. Gil-Castell, J. D. Badia, T. Kittikorn, E. Strömberg, A. Martínez-Felipe, M. Ek, S. Karlsson, A. Ribes-Greus. Hydrothermal ageing of polylactide/sisal biocomposites. Studies of water absorption behavior and physicochemical performance. Polymer Degradation and Stability 2014; 108, 212-222

${ }^{1}$ Instituto de Tecnología de los Materiales (ITM), Universidad Politècnica de València (UPV)

Camino de Vera S/N, 46022 Valencia, Spain.

${ }^{2}$ Departamentd'Enginyeria Química.

Escola Tècnica Superior d'Enginyeria. Universitat de València.

Av. de la Universitat, s/n, 46100, Burjassot, Spain.

${ }^{3}$ School of Chemical Science and Engineering, Fibre and Polymer Technology,

KTH - Royal Institute of Technology,

Teknikrigen 56-58, SE-10044 Stockholm, Sweden.

${ }^{4}$ Department of Materials Science and Technology,

Faculty of Science, Prince of Songkla University Songkhla, 90112, Thailand.

${ }^{5}$ Departamento de Química Orgánica, Facultad de Ciencias, Instituto de Ciencia de Materiales de Aragón (ICMA),

Universidad de Zaragoza-CSIC, Pedro Cerbuna, Zaragoza 50009, Spain.

${ }^{6}$ Skövde University, SE-541 28 Skövde, Sweden.

*Corresponding author: A. Ribes-Greus aribes@ter.upv.es 
O. Gil-Castell, J. D. Badia, T. Kittikorn, E. Strömberg, A. Martínez-Felipe, M. Ek, S. Karlsson, A. Ribes-Greus.

Hydrothermal ageing of polylactide/sisal biocomposites. Studies of water absorption behavior and physicochemical performance. Polymer Degradation and Stability 2014; 108, 212-222

\title{
HYDROTHERMAL AGEING OF POLYLACTIDE/SISAL BIOCOMPOSITES. STUDIES OF WATER ABSORPTION BEHAVIOUR AND PHYSICO- CHEMICAL PERFORMANCE
}

\author{
O. Gil-Castell ${ }^{1}$, J. D. Badia ${ }^{1,2}$, T. Kittikorn ${ }^{3,4}$, E. Strömberg ${ }^{3}$, A. Martínez-Felipe ${ }^{1,5}$, M. Ek ${ }^{3}$, \\ S. Karlsson ${ }^{3,6}$, A. Ribes-Greus ${ }^{1, *}$.
}

\begin{abstract}
An accelerated hydrothermal degrading test was designed in order to analyse the synergic effect of water and temperature on PLA/sisal biocomposites with and without coupling agent. As well, the physicochemical properties of biocomposites were monitored along the hydrothermal test by means of Scanning Electron Microscopy, Size Exclusion Chromatography and Differential Scanning Calorimetry. The addition of fibre induced higher water absorption capability and promoted physical degradation, as observed in the surface topography. During the processing of biocomposites and throughout the hydrothermal ageing, a reduction of molecular weight due to chain scission was found. As a consequence, a faster formation of crystalline domains in the PLA matrix occurred the higher the amount of fibre was, which acted as a nucleating agent. Higher crystallinity was considered as a barrier against the advance of penetrant and a reduction in the diffusion coefficient was shown. The addition of coupling agent presented a different influence depending on the composition, showing an inflection point around $20 \%$ of sisal fibre.
\end{abstract}

\section{Keywords}

Biocomposites, Polylactide (PLA), natural fibres, sisal, hydrothermal, degradation, water absorption, diffusion. 


\section{Introduction}

Poly(lactic acid) or polylactide (PLA) is a highly versatile, biodegradable polymer produced from agricultural bases such as corn, beets, wheat and other starchy products [1,2]. The development of fully biodegradable composite materials based on polylactide and natural fibres has been the aim for researchers in recent years [3-7]. In order to improve mechanical and thermal properties of the matrix, some natural fibres can be added, which provide reinforcement properties at low cost, low density and high strength and stiffness, environmental friendliness and health/safety factors [8-11]. However, due to the hygroscopic nature of the fibres, adverse effects may occur during the service life of biocomposites [12-14], mainly on the fibre-matrix interphase which can result in cracks and debonding, leading to the development of delaminations $[5,15]$.

The strength of the interfacial bond depends on many parameters, including the surface energy, chemistry and roughness of the fibre [16]. There are several alternatives to improve the moisture resistance. For instance, Hu et al. [17] prevented interphase of biocomposites from humidity by coating samples with a thin layer of polypropylene. Other ways to enhance hydrolysis resistance were tried by Kim et al. [18], by means of the addition of an anti-hydrolysis agent. They also tried to apply electron beam irradiation to a trifunctional monomer added during processing in order to promote macromolecule crosslinking. Le Duigou et al. [19] stated that the manufacturing route is also of great importance not directly in the water absorption kinetics but in other aspects such as mechanical properties of saturated samples. They processed PLA/flax biocomposites by injection moulding and by film stacking, demonstrating that the last process is less aggressive, and showed less degradation after saturation. Other works have shown that the thermal cycle can strongly influence interfacial behaviour. It was observed by Quan et al. [20] that a transcrystalline region can grow oriented perpendicular to the fibre in specific conditions.

The fibre-matrix interphase can also be improved by means of coupling agents, which are usually used to improve the hydrolytic resistance [21-23]. Polymers with functional groups such as $-\mathrm{OH},-\mathrm{COOH}$ in their chain ends, like PLA, and natural fibres with $-\mathrm{OH}$ groups, can be chemically coupled [24,25]. During the coupling process, small dispersed domains are formed, enhancing the interfacial adhesion and reducing the interfacial tension between two immiscible phases. Maleic anhydride (MAH) is one of the most widely used reactive compatibilizers due to its good chemical reactivity, low toxicity and low potential to polymerize itself under free radical grafting conditions [26].

An accelerated hydrothermal ageing process is a verified tool to assess the degradation behaviour for the composite materials [27-29]. The hydrolysis of PLA occurs by random cleavage of the $-\mathrm{C}-\mathrm{O}-$ ester bond by water molecules. This reaction can be increased under acidic or basic conditions or in the presence of high moisture and high temperature [30,31]. The hydrolysis products, which may contain fragments of lactic acid, oligomers and other water soluble products, can promote a catalysed reaction by the presence of carboxyl groups which change the $\mathrm{pH}$ of the material surroundings.

Previous studies [19] have shown that PLA and natural fibre reinforced composites are relatively stable in water at temperatures between $15^{\circ} \mathrm{C}$ and $45^{\circ} \mathrm{C}$, following a Fickian water uptake model. However, the simulation of hydrothermal treatments at higher temperatures near the glass transition allows understanding the PLA performance during their service life [27,32]. Temperatures between $65{ }^{\circ} \mathrm{C}$ and $85^{\circ} \mathrm{C}$ were chosen in this study to simulate the working 
O. Gil-Castell, J. D. Badia, T. Kittikorn, E. Strömberg, A. Martínez-Felipe, M. Ek, S. Karlsson, A. Ribes-Greus. Hydrothermal ageing of polylactide/sisal biocomposites. Studies of water absorption behavior and physicochemical performance. Polymer Degradation and Stability 2014; 108, 212-222

conditions of several applications, such as automobile interior panels. Thus, the aim of this study was to understand the combined influence of temperature, the amount of sisal fibre and the presence of coupling agent on the water absorption behaviour of reinforced PLA biocomposites, and to evaluate the impact on its physico-chemical properties. 
O. Gil-Castell, J. D. Badia, T. Kittikorn, E. Strömberg, A. Martínez-Felipe, M. Ek, S. Karlsson, A. Ribes-Greus.

Hydrothermal ageing of polylactide/sisal biocomposites. Studies of water absorption behavior and physicochemical performance. Polymer Degradation and Stability 2014; 108, 212-222

\section{Experimental procedure}

\subsection{Materials description and sample preparation}

Polylactide (PLA) 3251D was purchased from Natureworks (Minnetonka, USA) as pellets with a glass transition in $65-70{ }^{\circ} \mathrm{C}$ range. Sisal fibres which came from Thailand were a farming crop from the Thai Royal Project [33]. Their length was about 0.5-1 mm, tensile strength of 550 $\mathrm{MPa}$, tensile modulus of $30 \mathrm{GPa}$ and density about $1.5 \mathrm{~g} / \mathrm{cm}^{3}$. Dicumyl peroxide (DCP) $98 \%$ (Sigma-Aldrich, Sweden AB) and maleic anhydride (MAH) M188-99\% (Sigma-Aldrich, Sweden $\mathrm{AB}$ ) briquettes were used as free radical initiator and coupling agent, respectively.

Prior to processing, virgin PLA (VPLA) and sisal fibre were dried in an oven at $80{ }^{\circ} \mathrm{C}$ during at least 12 hours and kept in zip bags to prevent the presence of moisture during processing. The VPLA polymer and MA were prepared separately by grinding through a $1 \mathrm{~mm}$ sieve. The fibre contents in the biocomposite were formulated as $10 \%, 20 \%$ and $30 \%$ by weight with and without coupling agent. In case of not using $\mathrm{MAH}$, composites were prepared in an internal mixer (Brabender, Germany) during 5 minutes at $180{ }^{\circ} \mathrm{C}$ and $50 \mathrm{rpm}$ of speed. The resulting biocomposites were labelled as PLA10, PLA20 and PLA30. On the other hand, when coupling agent was used, MAH $2.5 \%$ and DCP $0.3 \%$ by weight were added in molten polymer. These percentages were chosen according to Hwang et al. [34] who suggested a better compatibilization for these quantities. After that, PLA matrix with coupling agent incorporated was mixed with fibres in the percentages described above during 5 minutes at $180{ }^{\circ} \mathrm{C}$ and 50 rpm of speed resulting in PLA10C, PLA20C and PLA30C.

The compounded PLA/sisal biocomposite was then ground and the granules dried at $80^{\circ} \mathrm{C}$ in the oven during at least 12 hours before further compression moulding, in order to avoid the hydrolysis degradation by moisture during the thermal process. Biocomposite probes were fabricated by using a compression moulding equipment (Fontijne Presses, Netherlands). The sheet shaped biocomposites preparation procedure consisted on preheating the press to $200{ }^{\circ} \mathrm{C}$ for $2 \mathrm{~min}$, and applying a compression force of $150 \mathrm{kN}$ during $2 \mathrm{~min}$. The thickness of the sheet samples was $0.5 \pm 0.1 \mathrm{~mm}$. All the operations were performed under vacuum conditions. Finally, all compounded biocomposites were dried in a vacuum oven and then kept in zip bags and placed in a desiccator for further analyses.

\subsection{Hydrothermal ageing procedure}

A normalized water absorption test reported in the ISO 62 - method 1 [35] was adopted as hydrothermal ageing environment, modifying the temperature specifications to the desired ageing conditions. Initially, the specimens were dried at $50{ }^{\circ} \mathrm{C}$ in a vacuum oven (Heraeus Vacutherm 6025) during $24 \mathrm{~h}$, and then kept in a desiccator at normalized lab conditions according to ISO 291 [36]. Samples of VPLA and composites were submerged into distilled water at three different temperatures $\left(65,75\right.$, and $\left.85^{\circ} \mathrm{C}\right)$ below and above the glass transition $\left(\sim 70{ }^{\circ} \mathrm{C}\right)$ and below the cold-crystallization of PLA $\left(\sim 105^{\circ} \mathrm{C}\right)[37]$.

\subsection{Analytical monitoring of hydrothermal ageing}

The hydrothermal ageing process was monitored by several techniques in order to evaluate effects of hydrothermal degrading conditions along the water absorption process, on the samples submitted to hydrothermal testing. Samples were analysed for different times during the assay for a given temperature and a given material, so the material could be analytically characterized 
along the whole process of hydrothermal degradation. These times of the water absorption assay were those corresponding to samples at $0,25,50$ and $100 \%$ of water saturation mass $\left(M_{S}\right)$, referred for each one of the materials.

\subsubsection{Water uptake}

After certain periods of time, the specimens were removed from water, gently wiped to get rid of surface moieties, then weighed by means of a scale (Mettler Toledo AB135-S) with a precision of $0.1 \mathrm{mg}$ and finally submerged back into water. Increment on the sample mass due to the water absorbed along the aging process $\left(M_{t}\right)$ was calculated according to Eq. (1).

$$
M_{t}=\frac{m_{t}-m_{0}}{m_{0}} \times 100
$$

where $m_{t}$ is the weight measured during aging and $m_{0}$ is the weight at the beginning.

In order to obtain comparable water absorption plots, the test extent was considered as the triple of the saturation time for the material with slower saturation rate, in order to assure that the mass uptake profiles got to an asymptotic line, meaning the completion of the saturation. Therefore, the saturation mass $M_{S}$ was taken as the $M_{t}$ at the equilibrium. The average content of absorbed water was calculated by quintuplicate by weigh difference.

The solution to Fick's law for diffusion is different depending on the geometric structure of the material under study [38]. For plane sheet geometry, if the mass uptake at time $t$ is used as $M_{t}$ and the water uptake at the equilibrium as $M_{S}$, Fick's law can be simplified using Stefan's approximation (Eq. (2)) [38]. This estimation is used for describing the earlier stages of water uptake, usually for $M_{t} / M_{S} \leq 0.5$.

$$
\frac{M_{t}}{M_{s}}=\frac{4}{l} \frac{D t}{\pi}^{1 / 2}
$$

where $D$ is the diffusion coefficient. By plotting the $M_{t} / M_{S}$ ratios as a function of the square root of time, the slope of the plot $\theta$ can be calculated, and $D$ calculated according to Eq. (3).

$$
D=0.0625 \pi l^{2} \theta^{2}
$$

\subsubsection{Field Emission Scanning Electron Microscopy (FE-SEM)}

The topography of the specimens was analysed by means of a Zeiss Ultra 55 Field Emission Scanning Electron Microscope (Oberkochen,Germany). The degraded and non-degraded samples were cut into small pieces and dried at $50{ }^{\circ} \mathrm{C}$ in a vacuum oven for $24 \mathrm{~h}$ and then kept in desiccator during $48 \mathrm{~h}$ before SEM sample preparation. The residual water content was expected to have vapored physical bonded water and only remain chemical bonded water. The pieces were mounted on metal studs and platinum sputter-coated layer during 10 seconds using a Leica EM MED020 high resolution sputter coater (Wetzlar, Germany). Testing was performed at room temperature with a $1 \mathrm{kV}$ voltage.

\subsubsection{Size exclusion chromatography (SEC)}

In order to monitor the loss of molecular weight of PLA and composites along the whole ageing process, size exclusion chromatography (SEC) analysis was performed. Samples were dissolved in chloroform (Fluka, purity of 99\%) with a concentration of $3-5 \mathrm{mg} / \mathrm{ml}$ at room temperature for 
$1 \mathrm{~h}$. This solution was filtered under vacuum over PTFE 0.45 micrometers pore membranes for removal of contaminants and fibres before injecting into the SEC column. The polymers were analysed by triplicate with a Verotech PL-GPC 50 Plus system equipped with a PL-RI Detector and two PLgel $5 \mu \mathrm{m}$ MIXED-D (300x7.5 mm) columns from Varian. The samples were injected with a PL-AS RT Autosampler for PL-GPC 50 Plus, in which chloroform was used as mobile phase $\left(1 \mathrm{ml} / \mathrm{min}, 30^{\circ} \mathrm{C}\right)$. The calibration was created using polystyrene standards with a narrow molecular weight distribution. Corrections for the flow rate fluctuations were made using toluene as an internal standard. Cirrus GPC Software as used to process data and obtain number-average molecular weight $\left(M_{n}\right)$ as well as polydispersity index $(P D I)$.

\subsubsection{Differential Scanning Calorimetry (DSC)}

Calorimetric data of non-degraded samples and those subjected to the hydrothermal ageing process were obtained by Differential Scanning Calorimetry by means of a Mettler-Toledo DSC 820 series (Columbus, $\mathrm{OH}$ ). The DSC equipment was calibrated following the procedure of In and $\mathrm{Zn}$ standards. The samples, with a mass of about $4 \mathrm{mg}$ were analysed between 0 and $200{ }^{\circ} \mathrm{C}$ with a heating rate of $10{ }^{\circ} \mathrm{C} / \mathrm{min}$. All experiments were run under nitrogen atmosphere $(50$ $\mathrm{ml} / \mathrm{min}$ ). The specimens were characterized at least by triplicate and the averages of temperatures and enthalpies were taken as representative values.

The PLA matrix relaxations associated to the glass transition, cold-crystallization and melting could be appreciated in the thermograms for all samples along the first heating scan. These three thermal events are typical for semi-crystalline PLA based composites [39]. The temperature $\left(T_{s r}\right.$ $\left.{ }_{P}\right)$ and enthalpy $\left(\Delta h_{s r}\right)$ associated to the structural relaxation were evaluated from its peak and area using constant integration limits and a smooth polynomial function (sp-line) as baseline. The cold crystallization and melting temperatures $\left(T_{c c}\right.$ and $\left.T_{m}\right)$ were determined from their peaks in thermograms and the enthalpies associated to those events $\left(\Delta h_{c c}\right.$ and $\left.\Delta h_{m}\right)$ were determined using constant integration limits. The degree of crystallinity $\left(X_{c}\right)$ was calculated by Eq. (4).

$$
X_{c}=\frac{1}{\left(1-m_{f}\right)} \frac{\left(\Delta h_{m}-\left|\Sigma \Delta h_{c c}\right|\right)}{\Delta h_{m 0}} \times 100
$$

where $\Delta h_{m 0}$ is the melting enthalpy for a $100 \%$ crystalline PLA $\left(93 \mathrm{~J} \cdot \mathrm{g}^{-1}[40]\right)$, and $\left(1-m_{f}\right)$ is the weight fraction of PLA. 
O. Gil-Castell, J. D. Badia, T. Kittikorn, E. Strömberg, A. Martínez-Felipe, M. Ek, S. Karlsson, A. Ribes-Greus. Hydrothermal ageing of polylactide/sisal biocomposites. Studies of water absorption behavior and physicochemical performance. Polymer Degradation and Stability 2014; 108, 212-222

\section{Results and discussion}

\subsection{Water uptake}

Figure 1 shows the percentage of water absorption $M_{t}$ for virgin PLA and composites at the three hydrothermal ageing temperatures $T_{H A}$ chosen for the study. Water absorption increased as the immersion time did until equilibrium was achieved. Under glass transition $\left(65^{\circ} \mathrm{C}\right)$, all curves displayed three stages, seeming to follow Fickian behaviour: fast sorption at the initial stage and slow sorption thereafter, followed by asymptotic saturation. However, at temperatures above $T_{g}\left(75\right.$ and $85^{\circ} \mathrm{C}$ ), more than three stages seems to take place, in accordance with bibliography [19,41]. This complex and non-Fickian behaviour has been attributed to the development of surface microcracks, through which water can swell fibres, resulting in capillarity phenomenon. As expected, higher temperatures seemed to accelerate the water uptake behaviour. This is in accordance with most of the moisture absorption studies on natural fibre composites [19,41,42]. When the $T_{H A}$ was increased, the water saturation time was greatly shortened (from $\sim 8000 \mathrm{~s}$ at lower temperatures to $\sim 3000 \mathrm{~s}$ at higher ones), which may be attributed to the different penetration rate of water into the material.
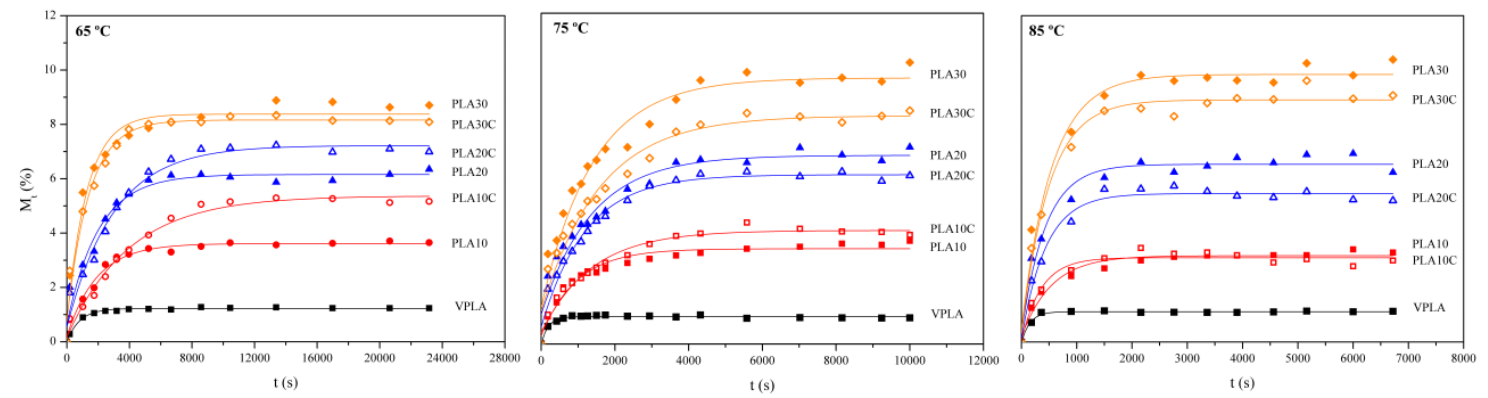

Figure 1. Water uptake profiles for VPLA and PLA/sisal biocomposites at all hydrothermal ageing temperatures. Note: all data relayed in a maximum $\sim 5 \%$ of experimental deviation.

For all $T_{H A}$, VPLA attained the minimum value of water absorbed $(\sim 1 \%)$. This value was in consonance with other studies, as reported by Wang. et al [43]. For all temperatures, it can be observed that in early stages of hydrothermal ageing, biocomposites gain much more weight than VPLA as a consequence of the cellulose present in sisal fibres [44]. The materials with higher sisal fibre (30\%) absorbed more water at saturation, reaching $\sim 10 \% M_{S}$.

For a given $T_{H A}$, sisal fibre in composites contributed to reach higher water saturation mass from $3 \%$ to $10 \%$, which may be attributed to its hydrophilic nature by virtue of the presence of an abundance of hydroxyl groups on the cellulose molecules which are available for interaction with water molecules [44]. Natural fibre can easily bond water molecules, thus resulting in higher water absorption.

In order to evaluate the influence of coupling agent, a comparative representation for VPLA and biocomposites at 65,75 and $85{ }^{\circ} \mathrm{C}$ is shown in Figure 2. As can be seen, the saturation mass $\left(M_{S}\right)$ presented a changing in trend for compositions around $20 \%$ of sisal fibre. 


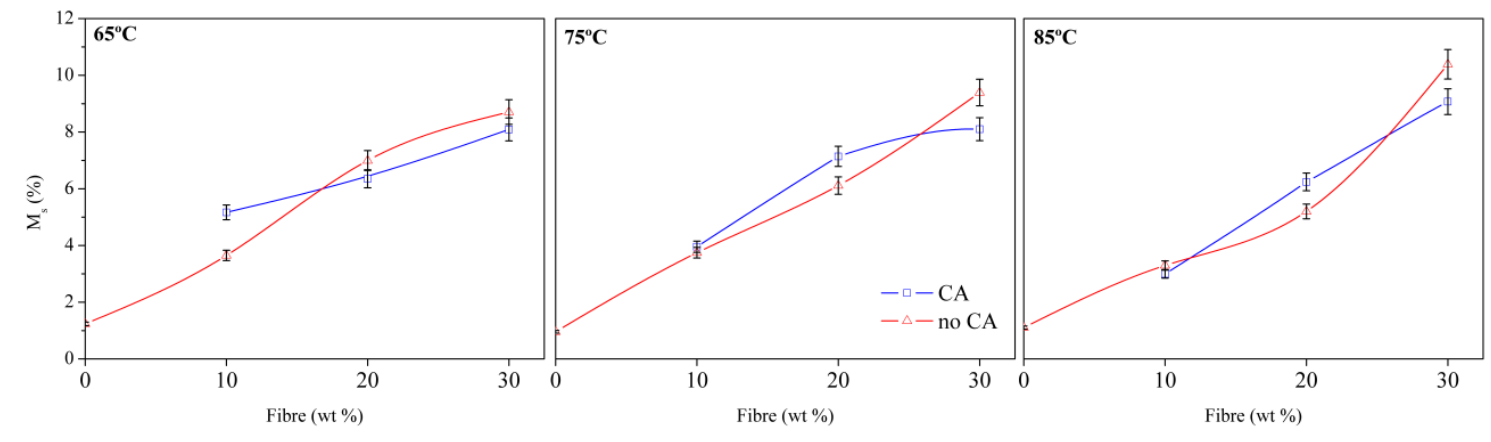

Figure 2. Water saturation mass $\left(M_{S}\right)$ for coupled and non-coupled PLA/sisal biocomposites at 65,75 and $85^{\circ} \mathrm{C}$. Note: all data relayed in a maximum $\sim 5 \%$ of experimental deviation.

\subsection{Water transport}

The water diffusion coefficients with the experimental standard deviation for PLA/sisal biocomposites are shown in Figure 3 for all hydrothermal ageing temperatures. The obtained values were comparable to those reported for polylactide in previous studies [32] and changed in the same order of magnitude with the addition of fibre, as reported in literature [41]. As expected, $D$ increased with $T_{H A}$ [45], more for VPLA (from $\sim 2 \cdot 10^{-7} \mathrm{~cm}^{2} \mathrm{~s}^{-1}$ to $\sim 9 \cdot 10^{-7} \mathrm{~cm}^{2} \mathrm{~s}^{-1}$ ) than for biocomposites (for PLA30 $D$ increased from $\sim 1.6 \cdot 10^{-7} \mathrm{~cm}^{2} \mathrm{~s}^{-1}$ to $\sim 2.2 \cdot 10^{-7} \mathrm{~cm}^{2} \mathrm{~s}^{-1}$ ).

The influence of sisal fibre and coupling agent in $D$ showed two well differentiated behaviours depending on $T_{H A}$.

Below the glass transition, the polymer chains maintained the morphology and structure determined by processing. In this case, a sinusoid tendency was observed when fibre content increased. However, when coupling agent (CA) was incorporated, the trend shape was similar, but for different compositions. This behaviour suggested a different effect of CA in $D$ depending on the amount of fibre, showing an inflection point around $20 \%$.

Above the glass transition, that behaviour disappeared, where the polymeric chains are in a lower energy state. An abrupt diminution of $D$ was shown when sisal fibre content increased, regardless of the presence of coupling agent. For those temperatures, although the hydrophilic character of fibres should indicate an increase of the diffusion coefficient, the reduction of $D$ suggested that some changes occurred in the internal structure of the composite. Those changes provoked an obstruction of the advance of penetrant along the composite sheet. This occurred as inorganic fibres were present [46]. Previous studies for PLA showed that only amorphous phase is permeable to water [47] while the crystal growing could be the cause of diffusion coefficient reduction [32]. As it was observed by Quan et al. [20], a transcrystalline region can grow oriented perpendicular to the fibre when temperature is increased, decreasing the transport paths of the water molecules and the water-interaction within the composite, resulting in global lower diffusion coefficients. 
O. Gil-Castell, J. D. Badia, T. Kittikorn, E. Strömberg, A. Martínez-Felipe, M. Ek, S. Karlsson, A. Ribes-Greus. Hydrothermal ageing of polylactide/sisal biocomposites. Studies of water absorption behavior and physicochemical performance. Polymer Degradation and Stability 2014; 108, 212-222

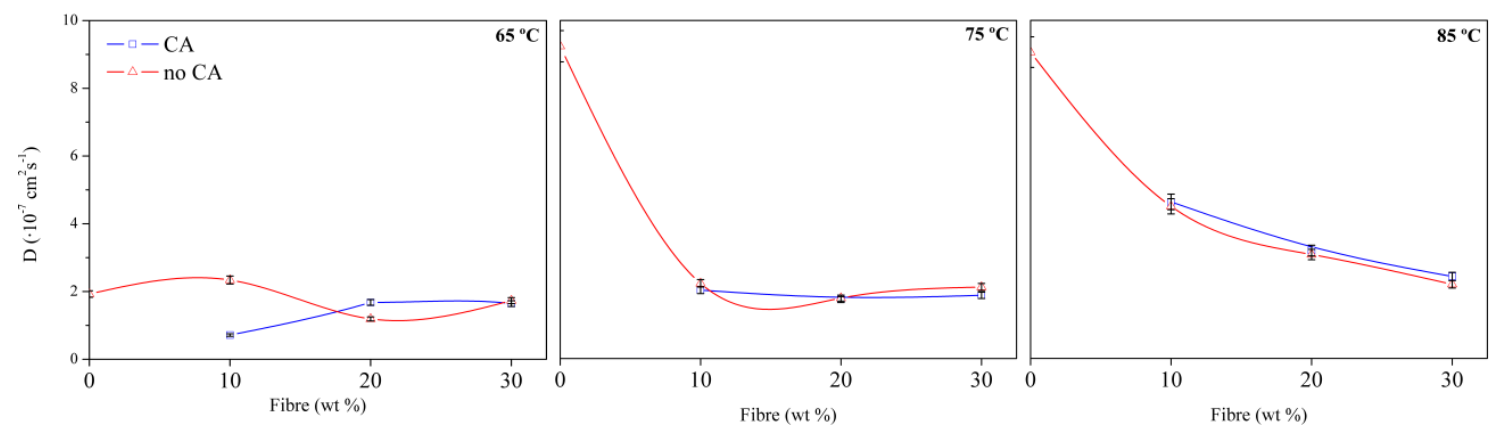

Figure 3. Diffusion coefficient for coupled and non-coupled PLA/sisal biocomposites at all hydrothermal ageing temperatures. Note: all data relied in a maximum $\sim 5 \%$ of experimental deviation.

\subsection{Physico-chemical performance}

The presence of water into the polymer matrices in combination with the temperature effect could be a cause of microstructure change and modification of the final performance of the PLA/sisal biocomposites. Plasticization of the amorphous regions, hydrolytic chain scission and/or crystallisation events that can promote a change on internal material structure were thus taken into account in this section.

\subsubsection{Surface topography}

In order to observe the topographical defects caused by the presence of fibre, coupling agent and the hydrothermal test, the PLA/sisal biocomposites were considered for being analysed by field emission scanning electron microscopy (FE-SEM). As example, Figure 4 displays the surface morphologies of VPLA and PLA/sisal biocomposites non-degraded and after the hydrothermal ageing process at $85^{\circ} \mathrm{C}$. The influence of coupling agent (CA) was assessed in PLA30/30C. The rest followed the same behaviour.

Before degradation, VPLA showed a neat surface, only altered by surface defects which may be caused during processing. A pattern of parallel lines was observed, due to the mechanisation of hot plates in which the material was processed. For PLA/sisal biocomposites, microcracks appeared on the surface due to the presence of sisal fibre, which caused mechanical damage to the PLA matrix. Moreover, a rougher surface is shown. When CA was incorporated, this cracking effect caused by sisal fibre seems to be smaller, and a smoother surface can be observed, probably due to a more cohesive structure and the plasticizing effect of MAH [34].

After hydrothermal ageing, a smoother surface was observed, due to the synergic effect of temperature and water which promoted a reorganisation of polymer chains in a more relaxed structure. In general terms, the analysis of the surface morphology showed physical degradation promoted by absorbed water. For VPLA, no cracks were observed after hydrothermal treatment at $85{ }^{\circ} \mathrm{C}$. This was not the case of the PLA/sisal biocomposites, in which cracking grew, more when the fibre content increased. As suggested by other authors [41,48-51], a differential swelling of fibre and matrix developed stress at interphase region, that leaded a microcracking mechanism in the matrix by swollen fibres.

The addition of CA produced a diminution of size of cracks and an apparent less degradation. It may suggest that structure of biocomposites is more cohesive and compacted. A better affinity between fibres and matrix seems to take place. However, microcracks and delamination still occurred but in a lesser extent. For the case of PLA30C shown in Figure 4, presence of coupling 
O. Gil-Castell, J. D. Badia, T. Kittikorn, E. Strömberg, A. Martínez-Felipe, M. Ek, S. Karlsson, A. Ribes-Greus. Hydrothermal ageing of polylactide/sisal biocomposites. Studies of water absorption behavior and physicochemical performance. Polymer Degradation and Stability 2014; 108, 212-222

agent not only contributed to reduce cracks, but also to reduce water saturation mass, as seen in water uptake section (Figure 1).

Non-degraded
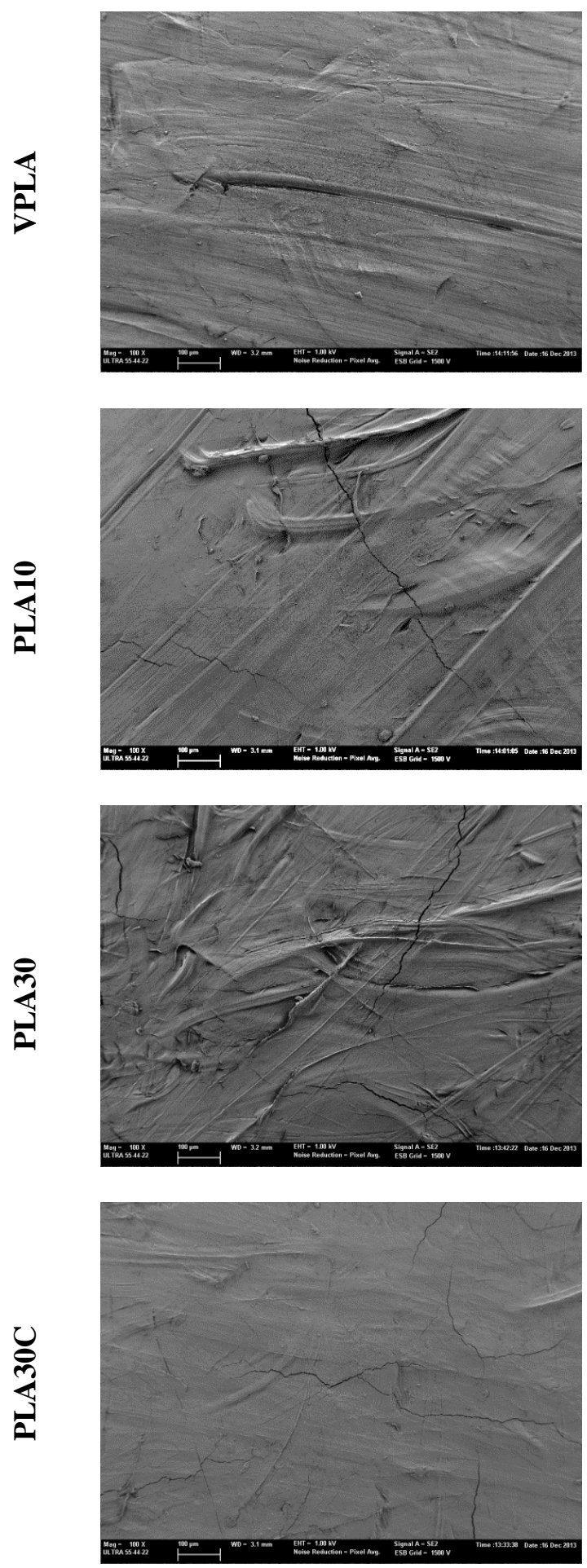

$85^{\circ} \mathrm{C}$
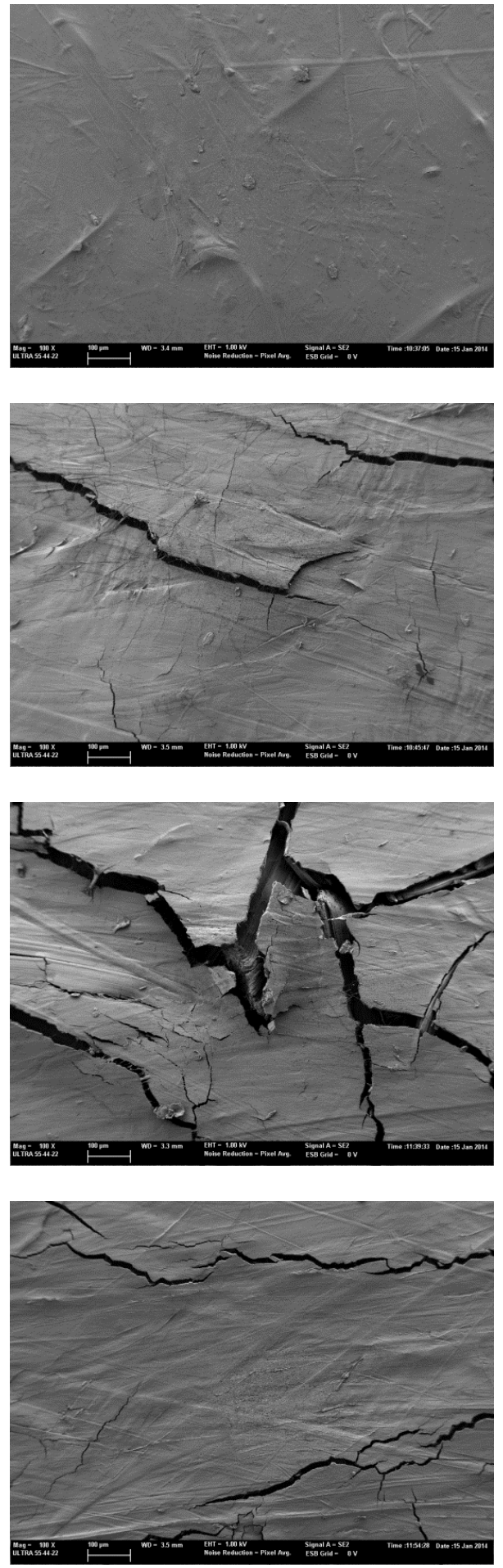

Figure 4. FE-SEM images for VPLA and PLA10, PLA20, PLA30 and PLA30C non-degraded and after hydrothermal ageing at $85^{\circ} \mathrm{C}(1 \mathrm{kV}, 100 \mathrm{x}$, Scale $100 \mu \mathrm{m})$. 


\subsubsection{Molecular weight}

Figure 5 shows the evolution of the number-average molecular weight $\left(M_{n}\right)$ and polydispersity index $(P D I)$ for all biocomposites subjected to hydrothermal ageing at 65,75 and $85^{\circ} \mathrm{C}$.

Before hydrothermal ageing, materials showed a linear reduction of the molecular weight when fibre percentage increased whilst a non-linear decrease was observed for composites with coupling agent (CA). Sisal fibre increased the viscosity and shear during processing which caused chain breakage, as suggested by Le Duigou et al. for injected PLA/flax biocomposites [19]. Particularly, the effect of CA in the reduction of $M_{n}$ was much more significant than the effect of fibre. It can be observed that coupled biocomposites (PLA10C, PLA20C and PLA30C) showed a similar reduction in molecular weight after processing ( $40 \%)$ compared to VPLA. The formation of radical species due to introduction of dycumyl peroxide (DCP) followed by a maleic anhydride (MAH) branching reaction could occur, leading to a decrease in number average molecular weight [34]. The increase of polidispersity index (PDI) may be due to the increase of cleavages of high molecular weight segments. Ester bond hydrolytic scission of PLA occurs randomly since longer chains of the polymer become more susceptible to cleavage than the shorter ones [30].

After hydrothermal process for all materials and temperatures, $M_{n}$ decreased significantly. The SEC analysis revealed that the degradation of PLA biocomposites was not linearly dependent on time of immersion. It was faster degraded in the early stage of water absorption and tended to decrease slowly thereafter. All saturated materials showed a reduction in $M_{n}$ between $30 \%$ and $50 \%$ with respect to non-degraded samples. The highest degradation rate during the first stage of immersion was due to a greater activity of water molecules as compared to equilibrium state [52]. A statistical chain breakage at the ester bond in the PLA and a depolymerisation process are the mechanisms which could result from that irreversible chemical degradation [53]. However, some changes occurred in the microstructure which acted as a barrier against water. Consequentially, the overall hydrolysis of polymeric phase was retarded.

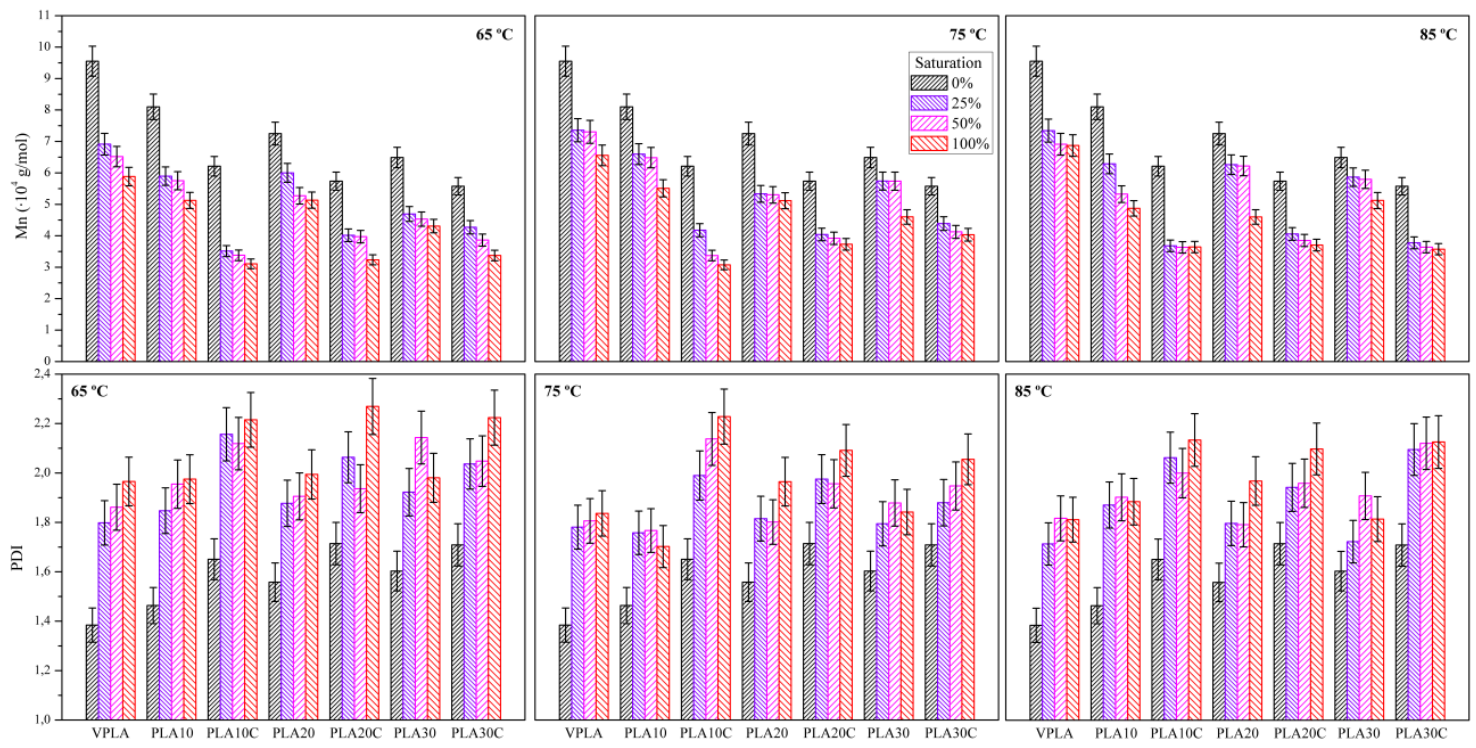

Figure 5. $M_{n}$ and PDI progress for VPLA and PLA/sisal biocomposites at different hydrothermal ageing temperatures. Numbers from 0 to $100 \%$ correspond to the respective saturation degrees. 


\subsubsection{Thermal properties and crystallinity}

Thermograms of the first heating scan are shown in Figure 6 and display the evolution of the main thermal events along the hydrothermal treatment $(0,25,50$ and $100 \%$ of saturation). Main temperatures and enthalpies are gathered in Tables 1, 2 and 3. Several remarks from these results are detailed for each thermal event: structural relaxation, cold-crystallization and melting.

The structural relaxation enthalpy $\left(\Delta h_{s r}\right)$ and its associated peak $\left(T_{s r-P}\right)$, related to the physical ageing phenomenon, decreased along the absorption process for all cases, reaching lower values for composites when fibre content increased. As can be seen in Figure 6, the decrease of $\Delta h_{s r}$ and $T_{s r-P}$ was faster for high temperatures, indicating a plasticizing effect of water in the polymer matrix [32], more important when water absorption increased.

With regards to the cold-crystallization phenomenon, its enthalpy $\left(\Delta h_{c c l}\right)$ and its peak temperature $\left(T_{c c l}\right)$ were evaluated. When the water saturation increased, $T_{c c l}$ was generally displaced to lower temperatures, between 1 to $7{ }^{\circ} \mathrm{C}$ as an indication of chain scission, due to the presence of shorter polymer chains. In addition, $\Delta h_{c c l}$ decreased until disappear for high water absorption. This phenomenon was accelerated by the presence of fibre and coupling agent, which might acted offering nucleating domains. In summary, during the water absorption process the potential crystallinity of each sample was reached, as also was observed in previous studies for reprocessed polylactide [32].

Finally, the melting enthalpy $\left(\Delta h_{m}\right)$ and its peak temperature $\left(T_{m}\right)$ were evaluated. $\Delta h_{m}$ slightly increased (no more than 15\%) while $T_{m}$ did not substantially change. That means that the melting process was similar for an equivalent crystalline nature. 
O. Gil-Castell, J. D. Badia, T. Kittikorn, E. Strömberg, A. Martínez-Felipe, M. Ek, S. Karlsson, A. Ribes-Greus. Hydrothermal ageing of polylactide/sisal biocomposites. Studies of water absorption behavior and physicochemical performance. Polymer Degradation and Stability 2014; 108, 212-222
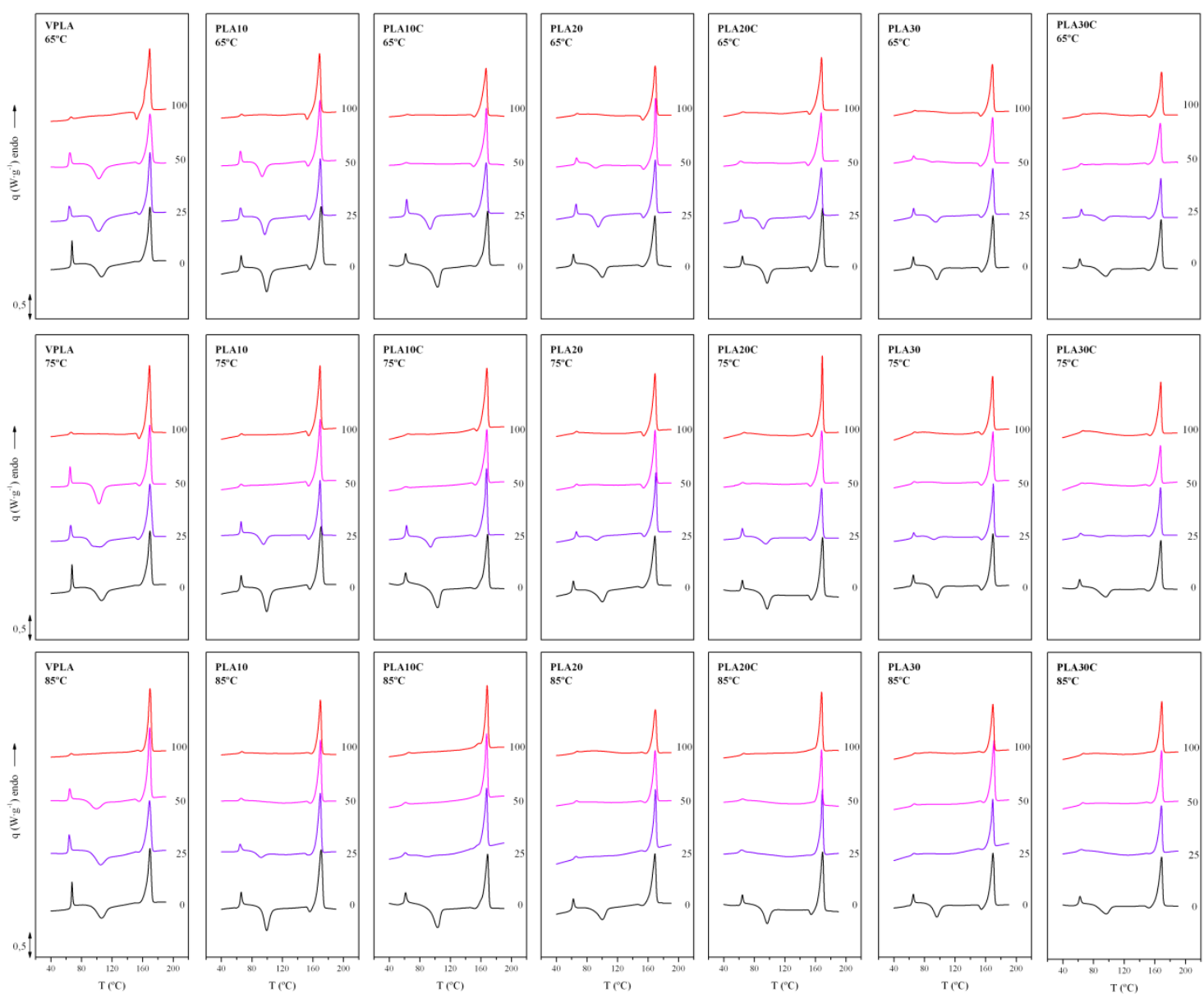

Figure 6. DSC traces of first heating scan for VPLA and PLA/sisal biocomposites at different hydrothermal ageing times and temperatures. Numbers from 0 to 100 correspond to the respective saturation degrees.

Regarding to the crystallinity degree $\left(X_{c}\right)$, it increased along the water absorption process which reached values between $40 \%$ and $45 \%$. In order to compare crystal growing rate, the parameter $X_{c} / X_{c s}$, can be assessed [32] where $X_{c s}$ is the value of the maximum potential crystallinity for each sample. In Figure 7, results of $X_{c} / X_{c s}$ are plotted against the hydrothermal ageing time. The achievement of the $X_{c s}$ was faster for $85^{\circ} \mathrm{C}$ than for 75 and $65^{\circ} \mathrm{C}$. This tendency was shown for all materials and temperatures, meaning that the composite structure changed during the hydrothermal treatment. The effect of interactions with water and temperature were likely to have enhanced the mobility of the PLA chains and acted as a driving force to form crystalline structures [32]. 
O. Gil-Castell, J. D. Badia, T. Kittikorn, E. Strömberg, A. Martínez-Felipe, M. Ek, S. Karlsson, A. Ribes-Greus. Hydrothermal ageing of polylactide/sisal biocomposites. Studies of water absorption behavior and physicochemical performance. Polymer Degradation and Stability 2014; 108, 212-222
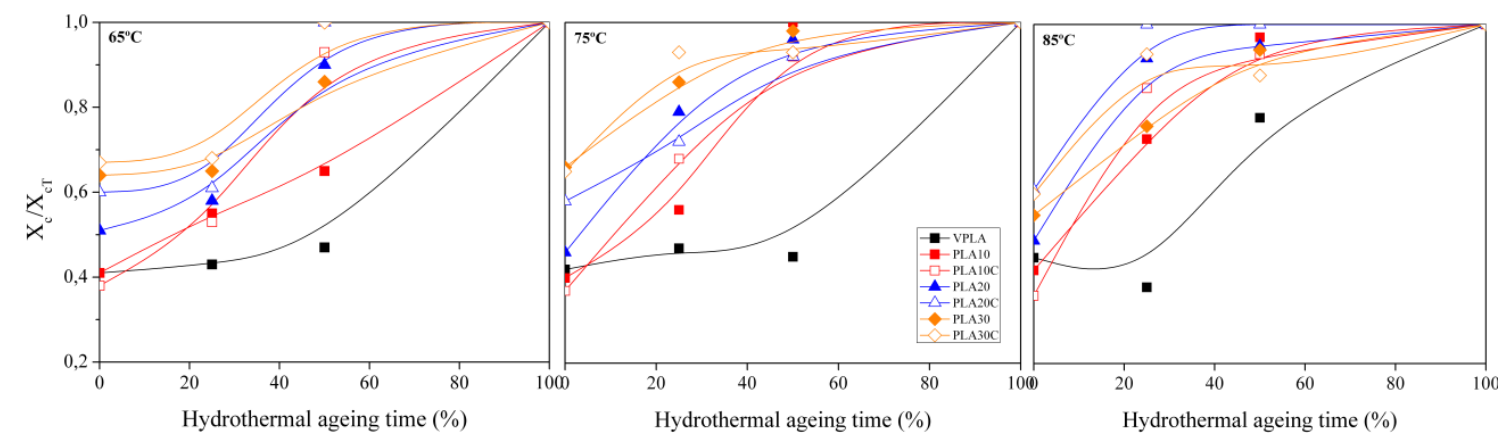

Figure 7. Evolution of the crystallinity degree for VPLA and PLA/sisal biocomposites at different hydrothermal ageing temperatures. Note: Error bars $( \pm 5 \%)$ have been omitted for the sake of clarity.

The presence of sisal fibre enhanced that behaviour, due to its ability to act as nucleating agent, promoting the formation of more crystalline phase. Figure 7 shows that the initial portion of crystalline phase of non-degraded samples was bigger for composites than for virgin PLA, suggesting that sisal fibres promoted the growth of crystalline phase during the processing of materials. As composites reached a bigger portion of their $X_{c s}$ during processing, the increment in crystallinity during the water absorption process was bigger for VPLA $(\sim 60 \%)$ than for composites $(\sim 30-50 \%)$.

As well as for the diffusion coefficient, the evolution of crystallinity showed an anomalous behaviour under glass transition $\left(65^{\circ} \mathrm{C}\right)$. Coupling agent had an atypical influence at this temperature. However, at 75 and $85^{\circ} \mathrm{C}$, crystallinity grew and diffusion decreased when fibre increased. Figure 8 shows that above $T_{g}$, the coupling agent slightly promoted more crystallisation. All these results are in concordance with the diffusion coefficient $D$ behaviour, which decreased when the fibre content increased. More crystal phase formation was favoured by sisal fibre which acted as a nucleating agent, hindering the advance of penetrant and decreasing the transport paths of the water molecules.

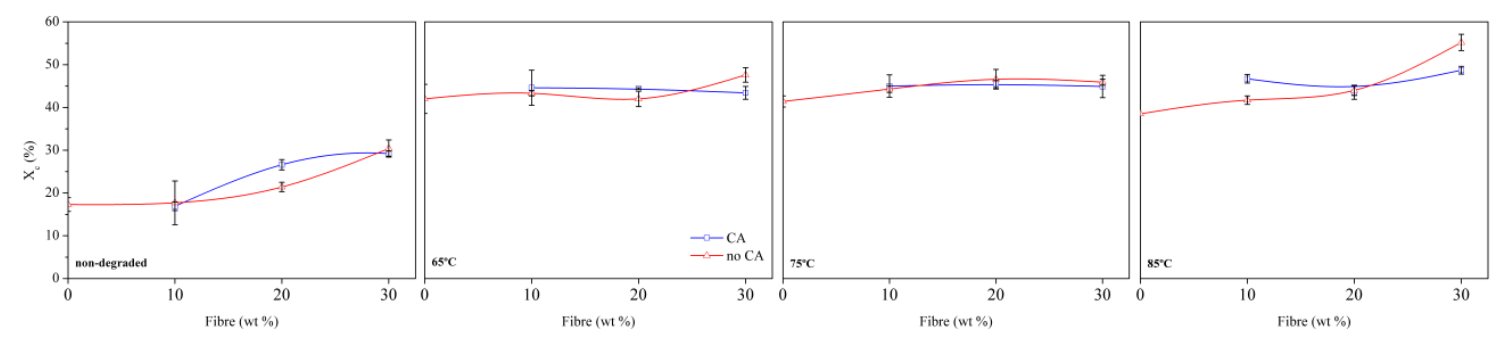

Figure 8. Crystallinity for VPLA and PLA/sisal biocomposites before degradation and after hydrothermal treatment at 65,75 and $85^{\circ} \mathrm{C}$. Note: all data relayed in a maximum $\sim 5 \%$ of experimental deviation. 
O. Gil-Castell, J. D. Badia, T. Kittikorn, E. Strömberg, A. Martínez-Felipe, M. Ek, S. Karlsson, A. Ribes-Greus. Hydrothermal ageing of polylactide/sisal biocomposites. Studies of water absorption behavior and physicochemical performance. Polymer Degradation and Stability 2014; 108, 212-222

Table 1. First heating scan data for VPLA and PLA/sisal biocomposites at $65^{\circ} \mathrm{C}$ and different saturation degrees.

\begin{tabular}{|c|c|c|c|c|c|c|c|c|c|c|c|c|c|c|c|c|c|}
\hline $65^{\circ} \mathrm{C}$ & Sat (\%) & \multicolumn{2}{|c|}{$\Delta \mathbf{h}_{\mathrm{sr}}(\mathrm{J} / \mathrm{g})$} & \multicolumn{2}{|c|}{$\mathbf{T}_{\text {sr-p }}\left({ }^{\circ} \mathrm{C}\right)$} & \multicolumn{2}{|c|}{$\Delta \mathbf{h}_{\mathrm{cc1}}(\mathbf{J} / \mathbf{g})$} & \multicolumn{2}{|c|}{$\mathbf{T}_{\mathrm{ccl}}\left({ }^{\circ} \mathrm{C}\right)$} & \multicolumn{2}{|c|}{$\Delta \mathbf{h}_{\mathrm{cc} 2}(\mathrm{~J} / \mathrm{g})$} & \multicolumn{2}{|c|}{$\mathbf{T}_{\mathrm{cc} 2}\left({ }^{\circ} \mathrm{C}\right)$} & \multicolumn{2}{|c|}{$\Delta \mathbf{h}_{\mathbf{m}}(\mathbf{J} / \mathbf{g})$} & \multicolumn{2}{|c|}{$\mathbf{T}_{\mathrm{m}}\left({ }^{\circ} \mathbf{C}\right)$} \\
\hline \multirow{4}{*}{ VPLA } & $\mathbf{0}$ & 5.9 & $( \pm 0.1)$ & 66.9 & $( \pm 0.2)$ & -19.4 & $( \pm 1.2)$ & 105.1 & $( \pm 0.3)$ & - & - & - & - & 35.5 & $( \pm 0.8)$ & 169.2 & $( \pm 0.1)$ \\
\hline & 25 & 5.8 & $( \pm 0.1)$ & 64.3 & $( \pm 0.5)$ & -19.7 & $( \pm 0.5)$ & 103.8 & $( \pm 1.4)$ & -0.7 & $( \pm 0.3)$ & 155.4 & $( \pm 0.1)$ & 37.1 & $( \pm 1.1)$ & 169.9 & $( \pm 0.4)$ \\
\hline & 50 & 5.5 & $( \pm 0.2)$ & 63.0 & $( \pm 1.6)$ & -21.3 & $( \pm 1.3)$ & 102.0 & $( \pm 0.3)$ & -1.0 & $( \pm 0.2)$ & 154.8 & $( \pm 0.1)$ & 40.5 & $( \pm 2.2)$ & 169.3 & $( \pm 0.1)$ \\
\hline & 100 & 0.8 & $( \pm 0.1)$ & - & - & - & - & - & - & -4.0 & $( \pm 0.2)$ & 151.7 & $( \pm 0.2)$ & 43.1 & $( \pm 1.5)$ & 168.8 & $( \pm 0.2)$ \\
\hline \multirow{4}{*}{ PLA10 } & 0 & 4.4 & $( \pm 0.4)$ & 66.8 & $( \pm 0.1)$ & -17.3 & $( \pm 1.9)$ & 98.0 & $( \pm 0.3)$ & -1.7 & $( \pm 0.2)$ & 154.9 & $( \pm 0.2)$ & 33.8 & $( \pm 2.6)$ & 169.0 & $( \pm 0.1)$ \\
\hline & 25 & 4.2 & $( \pm 0.0)$ & 64.8 & $( \pm 0.1)$ & -15.8 & $( \pm 0.5)$ & 96.7 & $( \pm 0.2)$ & -2.0 & $( \pm 0.1)$ & 154.8 & $( \pm 0.2)$ & 37.7 & $( \pm 1.0)$ & 169.5 & $( \pm 0.2)$ \\
\hline & 50 & 4.0 & $( \pm 0.1)$ & 64.9 & $( \pm 0.2)$ & -12.7 & $( \pm 0.4)$ & 93.7 & $( \pm 0.3)$ & -2.4 & $( \pm 0.1)$ & 153.4 & $( \pm 0.1)$ & 38.5 & $( \pm 1.1)$ & 168.9 & $( \pm 0.1)$ \\
\hline & 100 & 0.8 & $( \pm 0.1)$ & - & - & - & - & - & - & -3.1 & $( \pm 0.1)$ & 152.2 & $( \pm 0.1)$ & 39.4 & $( \pm 0.1)$ & 168.5 & $( \pm 0.2)$ \\
\hline \multirow{4}{*}{ PLA10C } & $\mathbf{0}$ & 6.2 & $( \pm 0.1)$ & 62.8 & $( \pm 0.2)$ & -21.7 & $( \pm 0.5)$ & 98.9 & $( \pm 0.5)$ & - & - & - & - & 35.5 & $( \pm 1.3)$ & 166.9 & $( \pm 0.3)$ \\
\hline & 25 & 4.7 & $( \pm 0.5)$ & 62.9 & $( \pm 0.4)$ & -15.7 & $( \pm 0.6)$ & 93.7 & $( \pm 0.4)$ & -1.7 & $( \pm 0.1)$ & 150.7 & $( \pm 0.4)$ & 36.9 & $( \pm 1.9)$ & 167.0 & $( \pm 0.2)$ \\
\hline & 50 & 0.8 & $( \pm 0.1)$ & 61.6 & $( \pm 0.2)$ & - & - & - & - & -1.3 & $( \pm 0.1)$ & 149.9 & $( \pm 0.3)$ & 35.4 & $( \pm 1.1)$ & 166.5 & $( \pm 0.1)$ \\
\hline & 100 & 0.4 & $( \pm 0.1)$ & - & - & - & - & - & - & -0.9 & $( \pm 0.1)$ & 150.9 & $( \pm 0.1)$ & 37.5 & $( \pm 2.8)$ & 166.4 & $( \pm 0.2)$ \\
\hline \multirow{4}{*}{ PLA20 } & $\mathbf{0}$ & 4.2 & $( \pm 0.3)$ & 67.2 & $( \pm 0.1)$ & -15.8 & $( \pm 0.6)$ & 96.3 & $( \pm 0.1)$ & -2.0 & $( \pm 0.3)$ & 154.1 & $( \pm 0.3)$ & 33.4 & $( \pm 0.9)$ & 168.9 & $( \pm 0.1)$ \\
\hline & 25 & 3.4 & $( \pm 0.1)$ & 65.4 & $( \pm 0.2)$ & -12.2 & $( \pm 0.9)$ & 94.3 & $( \pm 0.2)$ & -2.5 & $( \pm 0.1)$ & 154.0 & $( \pm 0.1)$ & 32.5 & $( \pm 0.7)$ & 169.1 & $( \pm 0.2)$ \\
\hline & 50 & 1.9 & $( \pm 0.2)$ & 65.8 & $( \pm 0.3)$ & -4.1 & $( \pm 0.2)$ & 90.6 & $( \pm 0.2)$ & -2.0 & $( \pm 0.4)$ & 153.5 & $( \pm 0.5)$ & 33.5 & $( \pm 0.2)$ & 169.1 & $( \pm 0.3)$ \\
\hline & 100 & 0.7 & $( \pm 0.1)$ & - & - & - & - & - & - & -2.5 & $( \pm 0.1)$ & 153.0 & $( \pm 0.1)$ & 33.0 & $( \pm 0.9)$ & 169.1 & $( \pm 0.2)$ \\
\hline \multirow{4}{*}{ PLA20C } & $\mathbf{0}$ & 2.1 & $( \pm 0.5)$ & 67.7 & $( \pm 0.2)$ & -6.5 & $( \pm 0.4)$ & 95.3 & $( \pm 0.1)$ & -1.5 & $( \pm 0.1)$ & 154.2 & $( \pm 0.1)$ & 27.8 & $( \pm 0.4)$ & 169.2 & $( \pm 0.1)$ \\
\hline & 25 & 4.3 & $( \pm 0.1)$ & 62.4 & $( \pm 0.3)$ & -11.8 & $( \pm 0.1)$ & 92.0 & $( \pm 0.7)$ & -1.2 & $( \pm 0.3)$ & 151.7 & $( \pm 0.3)$ & 33.3 & $( \pm 0.7)$ & 167.6 & $( \pm 0.1)$ \\
\hline & 50 & 1.7 & $( \pm 0.1)$ & 60.9 & $( \pm 0.3)$ & - & - & - & - & -1.4 & $( \pm 0.1)$ & 150.0 & $( \pm 0.1)$ & 36.0 & $( \pm 0.5)$ & 166.7 & $( \pm 0.4)$ \\
\hline & 100 & 0.8 & $( \pm 0.1)$ & - & - & - & - & - & - & -1.5 & $( \pm 0.2)$ & 151.7 & $( \pm 0.2)$ & 34.5 & $( \pm 0.3)$ & 167.8 & $( \pm 0.1)$ \\
\hline \multirow{4}{*}{ PLA30 } & 0 & 2.5 & $( \pm 0.4)$ & 67.6 & $( \pm 0.1)$ & -6.5 & $( \pm 2.9)$ & 95.3 & $( \pm 0.8)$ & -1.5 & $( \pm 0.3)$ & 154.2 & $( \pm 0.2)$ & 27.8 & $( \pm 1.3)$ & 169.2 & $( \pm 0.2)$ \\
\hline & 25 & 2.2 & $( \pm 0.1)$ & 65.7 & $( \pm 0.1)$ & -7.7 & $( \pm 0.5)$ & 94.6 & $( \pm 0.1)$ & -1.7 & $( \pm 0.1)$ & 154.0 & $( \pm 0.1)$ & 29.5 & $( \pm 0.3)$ & 169.1 & $( \pm 0.1)$ \\
\hline & 50 & 1.4 & $( \pm 0.1)$ & 65.5 & $( \pm 0.1)$ & - & - & - & - & -2.0 & $( \pm 0.1)$ & 153.3 & $( \pm 0.1)$ & 28.8 & $( \pm 0.2)$ & 169.0 & $( \pm 0.2)$ \\
\hline & 100 & 0.4 & $( \pm 0.1)$ & - & - & - & - & - & - & -1.5 & $( \pm 0.1)$ & 153.5 & $( \pm 0.1)$ & 32.5 & $( \pm 0.9)$ & 168.9 & $( \pm 0.3)$ \\
\hline \multirow{4}{*}{ PLA30C } & $\mathbf{0}$ & 3.2 & $( \pm 0.1)$ & 65.6 & $( \pm 0.5)$ & -9.8 & $( \pm 0.2)$ & 93.3 & $( \pm 0.7)$ & -1.0 & $( \pm 0.1)$ & 152.8 & $( \pm 0.4)$ & 29.3 & $( \pm 0.3)$ & 168.1 & $( \pm 0.4)$ \\
\hline & 25 & 2.6 & $( \pm 0.2)$ & 63.4 & $( \pm 0.8)$ & -6.0 & $( \pm 0.2)$ & 91.5 & $( \pm 1.5)$ & -0.8 & $( \pm 0.1)$ & 151.9 & $( \pm 0.3)$ & 25.4 & $( \pm 1.5)$ & 167.7 & $( \pm 0.5)$ \\
\hline & 50 & 1.7 & $( \pm 0.1)$ & 60.9 & $( \pm 0.3)$ & - & - & - & - & -0.7 & $( \pm 0.1)$ & 151.4 & $( \pm 0.1)$ & 28.1 & $( \pm 0.3)$ & 167.3 & $( \pm 0.1)$ \\
\hline & 100 & 0.3 & $( \pm 0.1)$ & - & - & - & - & - & - & -0.9 & $( \pm 0.2)$ & 152.9 & $( \pm 0.2)$ & 28.4 & $( \pm 0.2)$ & 168.6 & $( \pm 0.7)$ \\
\hline
\end{tabular}


O. Gil-Castell, J. D. Badia, T. Kittikorn, E. Strömberg, A. Martínez-Felipe, M. Ek, S. Karlsson, A. Ribes-Greus. Hydrothermal ageing of polylactide/sisal biocomposites. Studies of water absorption behavior and physicochemical performance. Polymer Degradation and Stability 2014; 108, 212-222

Table 2. First heating scan data for VPLA and PLA/sisal biocomposites at $75^{\circ} \mathrm{C}$ and different saturation degrees.

\begin{tabular}{|c|c|c|c|c|c|c|c|c|c|c|c|c|c|c|c|c|c|}
\hline $75^{\circ} \mathrm{C}$ & Sat (\%) & \multicolumn{2}{|c|}{$\Delta \mathbf{h}_{\mathrm{sr}}(\mathrm{J} / \mathrm{g})$} & \multicolumn{2}{|c|}{$\mathbf{T}_{\text {sr-p }}\left({ }^{\circ} \mathrm{C}\right)$} & \multicolumn{2}{|c|}{$\Delta \mathbf{h}_{\mathrm{cc1}}(\mathbf{J} / \mathbf{g})$} & \multicolumn{2}{|c|}{$\mathbf{T}_{\mathrm{ccl}}\left({ }^{\circ} \mathrm{C}\right)$} & \multicolumn{2}{|c|}{$\Delta \mathbf{h}_{\mathrm{cc} 2}(\mathrm{~J} / \mathrm{g})$} & \multicolumn{2}{|c|}{$\mathbf{T}_{\mathrm{cc} 2}\left({ }^{\circ} \mathrm{C}\right)$} & \multicolumn{2}{|c|}{$\Delta \mathbf{h}_{\mathbf{m}}(\mathbf{J} / \mathbf{g})$} & \multicolumn{2}{|c|}{$\mathbf{T}_{\mathrm{m}}\left({ }^{\circ} \mathbf{C}\right)$} \\
\hline \multirow{4}{*}{ VPLA } & $\mathbf{0}$ & 5.9 & $( \pm 0.1)$ & 66.9 & $( \pm 0.2)$ & -19.4 & $( \pm 1.2)$ & 105.1 & $( \pm 0.3)$ & - & - & - & - & 35.5 & $( \pm 0.8)$ & 169.2 & $( \pm 0.1)$ \\
\hline & 25 & 4.3 & $( \pm 0.4)$ & 65.8 & $( \pm 0.4)$ & -16.9 & $( \pm 2.8)$ & 104.9 & $( \pm 2.4)$ & -0.7 & $( \pm 0.4)$ & 153.8 & $( \pm 0.3)$ & 35.9 & $( \pm 4.0)$ & 169.8 & $( \pm 0.7)$ \\
\hline & 50 & 4.4 & $( \pm 0.1)$ & 64.8 & $( \pm 0.1)$ & -19.2 & $( \pm 4.8)$ & 103.2 & $( \pm 0.3)$ & -0.8 & $( \pm 0.1)$ & 155.3 & $( \pm 0.1)$ & 37.2 & $( \pm 0.5)$ & 168.9 & $( \pm 0.2)$ \\
\hline & 100 & 1.0 & $( \pm 0.1)$ & - & - & - & - & - & - & -2.6 & $( \pm 0.3)$ & 154.4 & $( \pm 0.3)$ & 41.2 & $( \pm 1.0)$ & 168.4 & $( \pm 0.1)$ \\
\hline \multirow{4}{*}{ PLA10 } & 0 & 4.4 & $( \pm 0.4)$ & 66.8 & $( \pm 0.1)$ & -17.3 & $( \pm 1.9)$ & 98.0 & $( \pm 0.3)$ & -1.7 & $( \pm 0.2)$ & 154.9 & $( \pm 0.2)$ & 33.8 & $( \pm 2.6)$ & 169.0 & $( \pm 0.1)$ \\
\hline & 25 & 3.0 & $( \pm 0.1)$ & 65.6 & $( \pm 0.1)$ & -12.2 & $( \pm 1.0)$ & 95.6 & $( \pm 0.6)$ & -2.5 & $( \pm 0.1)$ & 154.2 & $( \pm 0.1)$ & 35.5 & $( \pm 2.4)$ & 169.3 & $( \pm 0.3)$ \\
\hline & 50 & 1.1 & $( \pm 0.1)$ & 65.9 & $( \pm 0.3)$ & - & - & - & - & -1.9 & $( \pm 0.1)$ & 154.5 & $( \pm 0.4)$ & 39.0 & $( \pm 0.4)$ & 169.9 & $( \pm 0.8)$ \\
\hline & 100 & 0.8 & $( \pm 0.1)$ & - & - & - & - & - & - & -2.4 & $( \pm 0.1)$ & 154.4 & $( \pm 0.3)$ & 39.5 & $( \pm 0.6)$ & 169.0 & $( \pm 0.1)$ \\
\hline \multirow{4}{*}{ PLA10C } & $\mathbf{0}$ & 6.2 & $( \pm 0.1)$ & 62.8 & $( \pm 0.2)$ & -21.7 & $( \pm 0.5)$ & 98.9 & $( \pm 0.5)$ & - & - & - & - & 35.5 & $( \pm 1.3)$ & 166.9 & $( \pm 0.3)$ \\
\hline & 25 & 4.6 & $( \pm 0.1)$ & 61.8 & $( \pm 0.5)$ & -10.7 & $( \pm 0.2)$ & 92.8 & $( \pm 1.0)$ & -0.9 & $( \pm 0.2)$ & 151.8 & $( \pm 0.3)$ & 36.8 & $( \pm 2.5)$ & 166.5 & $( \pm 0.3)$ \\
\hline & 50 & 0.6 & $( \pm 0.1)$ & 60.1 & $( \pm 1.0)$ & - & - & - & - & -0.7 & $( \pm 0.2)$ & 151.8 & $( \pm 0.5)$ & 34.6 & $( \pm 1.2)$ & 166.4 & $( \pm 1.1)$ \\
\hline & 100 & 0.6 & $( \pm 0.1)$ & - & - & - & - & - & - & -0.7 & $( \pm 0.1)$ & 154.0 & $( \pm 0.1)$ & 37.5 & $( \pm 2.1)$ & 167.4 & $( \pm 0.1)$ \\
\hline \multirow{4}{*}{ PLA20 } & $\mathbf{0}$ & 4.2 & $( \pm 0.3)$ & 67.2 & $( \pm 0.1)$ & -15.8 & $( \pm 0.6)$ & 96.3 & $( \pm 0.1)$ & -2.0 & $( \pm 0.3)$ & 154.1 & $( \pm 0.3)$ & 33.4 & $( \pm 0.9)$ & 168.9 & $( \pm 0.1)$ \\
\hline & 25 & 1.9 & $( \pm 0.1)$ & 65.6 & $( \pm 0.3)$ & -4.2 & $( \pm 0.5)$ & 92.1 & $( \pm 0.2)$ & -2.0 & $( \pm 0.1)$ & 154.4 & $( \pm 0.2)$ & 32.7 & $( \pm 1.7)$ & 169.5 & $( \pm 0.3)$ \\
\hline & 50 & 0.7 & $( \pm 0.1)$ & 66.3 & $( \pm 0.1)$ & - & - & - & - & -1.9 & $( \pm 0.1)$ & 154.0 & $( \pm 0.1)$ & 34.3 & $( \pm 0.7)$ & 169.1 & $( \pm 0.1)$ \\
\hline & 100 & 0.7 & $( \pm 0.1)$ & - & - & - & - & - & - & -1.4 & $( \pm 0.3)$ & 154.2 & $( \pm 0.3)$ & 35.2 & $( \pm 1.4)$ & 169.4 & $( \pm 0.6)$ \\
\hline \multirow{4}{*}{ PLA20C } & $\mathbf{0}$ & 2.1 & $( \pm 0.5)$ & 67.7 & $( \pm 0.2)$ & -6.5 & $( \pm 0.4)$ & 95.3 & $( \pm 0.1)$ & -1.5 & $( \pm 0.1)$ & 154.2 & $( \pm 0.1)$ & 27.8 & $( \pm 0.4)$ & 169.2 & $( \pm 0.1)$ \\
\hline & 25 & 3.1 & $( \pm 0.1)$ & 63.6 & $( \pm 0.5)$ & -7.7 & $( \pm 0.7)$ & 94.1 & $( \pm 0.8)$ & -1.1 & $( \pm 0.1)$ & 152.5 & $( \pm 0.1)$ & 32.9 & $( \pm 0.3)$ & 167.8 & $( \pm 0.1)$ \\
\hline & 50 & 0.8 & $( \pm 0.1)$ & 64.3 & $( \pm 0.2)$ & - & - & - & - & -1.7 & $( \pm 0.1)$ & 153.3 & $( \pm 0.2)$ & 33.0 & $( \pm 1.7)$ & 168.0 & $( \pm 0.1)$ \\
\hline & 100 & 0.4 & $( \pm 0.1)$ & - & - & - & - & - & - & -1.7 & $( \pm 0.1)$ & 155.0 & $( \pm 0.3)$ & 35.6 & $( \pm 0.7)$ & 169.2 & $( \pm 0.6)$ \\
\hline \multirow{4}{*}{ PLA30 } & 0 & 2.5 & $( \pm 0.4)$ & 67.6 & $( \pm 0.1)$ & -6.5 & $( \pm 2.9)$ & 95.3 & $( \pm 0.8)$ & -1.5 & $( \pm 0.3)$ & 154.2 & $( \pm 0.2)$ & 27.8 & $( \pm 1.3)$ & 169.2 & $( \pm 0.2)$ \\
\hline & 25 & 1.0 & $( \pm 0.4)$ & 65.1 & $( \pm 0.3)$ & -3.6 & $( \pm 0.6)$ & 91.5 & $( \pm 0.4)$ & -1.8 & $( \pm 0.1)$ & 154.0 & $( \pm 0.2)$ & 31.0 & $( \pm 2.0)$ & 168.9 & $( \pm 0.7)$ \\
\hline & 50 & 0.4 & $( \pm 0.1)$ & 66.0 & $( \pm 0.1)$ & - & - & - & - & -1.7 & $( \pm 0.2)$ & 153.9 & $( \pm 0.4)$ & 31.1 & $( \pm 0.1)$ & 169.0 & $( \pm 0.6)$ \\
\hline & 100 & 0.3 & $( \pm 0.1)$ & - & - & - & - & - & - & -1.5 & $( \pm 0.2)$ & 154.6 & $( \pm 0.1)$ & 31.4 & $( \pm 0.3)$ & 168.5 & $( \pm 0.1)$ \\
\hline \multirow{4}{*}{ PLA30C } & $\mathbf{0}$ & 3.2 & $( \pm 0.1)$ & 65.6 & $( \pm 0.5)$ & -9.8 & $( \pm 0.2)$ & 93.3 & $( \pm 0.7)$ & -1.0 & $( \pm 0.1)$ & 152.8 & $( \pm 0.4)$ & 29.3 & $( \pm 0.3)$ & 168.1 & $( \pm 0.4)$ \\
\hline & 25 & 1.4 & $( \pm 0.1)$ & 63.4 & $( \pm 0.2)$ & -1.9 & $( \pm 0.2)$ & 89.8 & $( \pm 1.0)$ & -1.0 & $( \pm 0.1)$ & 153.0 & $( \pm 0.1)$ & 29.3 & $( \pm 0.3)$ & 168.1 & $( \pm 0.1)$ \\
\hline & 50 & 0.4 & $( \pm 0.1)$ & 64.3 & $( \pm 0.4)$ & - & - & - & - & -0.9 & $( \pm 0.3)$ & 153.7 & $( \pm 0.1)$ & 27.4 & $( \pm 0.9)$ & 167.7 & $( \pm 0.3)$ \\
\hline & 100 & 0.3 & $( \pm 0.1)$ & - & - & - & - & - & - & -0.7 & $( \pm 0.1)$ & 154.1 & $( \pm 0.1)$ & 29.1 & $( \pm 1.6)$ & 167.9 & $( \pm 0.4)$ \\
\hline
\end{tabular}


O. Gil-Castell, J. D. Badia, T. Kittikorn, E. Strömberg, A. Martínez-Felipe, M. Ek, S. Karlsson, A. Ribes-Greus. Hydrothermal ageing of polylactide/sisal biocomposites. Studies of water absorption behavior and physicochemical performance. Polymer Degradation and Stability 2014; 108, 212-222

Table 3. First heating scan data for VPLA and PLA/sisal biocomposites at $85^{\circ} \mathrm{C}$ and different saturation degrees.

\begin{tabular}{|c|c|c|c|c|c|c|c|c|c|c|c|c|c|c|c|c|c|}
\hline $85^{\circ} \mathrm{C}$ & Sat (\%) & \multicolumn{2}{|c|}{$\Delta \mathbf{h}_{\text {sr }}(\mathbf{J} / \mathbf{g})$} & \multicolumn{2}{|c|}{$\mathbf{T}_{\text {sr-p }}\left({ }^{\circ} \mathrm{C}\right)$} & \multicolumn{2}{|c|}{$\Delta \mathbf{h}_{\mathrm{cc1}}(\mathrm{J} / \mathbf{g})$} & \multicolumn{2}{|c|}{$\mathbf{T}_{\mathrm{ccl}}\left({ }^{\circ} \mathrm{C}\right)$} & \multicolumn{2}{|c|}{$\Delta \mathbf{h}_{\mathrm{cc} 2}(\mathbf{J} / \mathbf{g})$} & \multicolumn{2}{|c|}{$\mathbf{T}_{\mathrm{cc} 2}\left({ }^{\circ} \mathrm{C}\right)$} & \multicolumn{2}{|c|}{$\Delta \mathbf{h}_{\mathrm{m}}(\mathbf{J} / \mathbf{g})$} & \multicolumn{2}{|c|}{$\mathbf{T}_{\mathrm{m}}\left({ }^{\circ} \mathbf{C}\right)$} \\
\hline \multirow{4}{*}{ VPLA } & $\mathbf{0}$ & 5.9 & $( \pm 0.1)$ & 66.9 & $( \pm 0.2)$ & -19.4 & $( \pm 1.2)$ & 105.1 & $( \pm 0.3)$ & - & - & - & - & 35.5 & $( \pm 0.8)$ & 169.2 & $( \pm 0.1)$ \\
\hline & 25 & 4.8 & $( \pm 0.8)$ & 63.8 & $( \pm 0.1)$ & -21.4 & $( \pm 0.5)$ & 103.4 & $( \pm 1.2)$ & -0.6 & $( \pm 0.2)$ & 155.3 & $( \pm 0.1)$ & 35.8 & $( \pm 1.1)$ & 168.9 & $( \pm 0.3)$ \\
\hline & 50 & 2.6 & $( \pm 0.6)$ & 64.2 & $( \pm 0.1)$ & -9.3 & $( \pm 5.4)$ & 96.2 & $( \pm 2.9)$ & -1.8 & $( \pm 0.7)$ & 154.9 & $( \pm 0.2)$ & 38.9 & $( \pm 2.4)$ & 168.8 & $( \pm 0.1)$ \\
\hline & 100 & 0.8 & $( \pm 0.1)$ & - & - & - & - & - & - & - & - & - & - & 35.9 & $( \pm 0.1)$ & 169.5 & $( \pm 0.2)$ \\
\hline \multirow{4}{*}{ PLA10 } & 0 & 4.4 & $( \pm 0.4)$ & 66.8 & $( \pm 0.0)$ & -17.3 & $( \pm 1.9)$ & 98.0 & $( \pm 0.3)$ & -1.7 & $( \pm 0.2)$ & 154.9 & $( \pm 0.2)$ & 33.8 & $( \pm 2.6)$ & 169.0 & $( \pm 0.1)$ \\
\hline & 25 & 3.1 & $( \pm 0.3)$ & 64.3 & $( \pm 0.1)$ & -8.4 & $( \pm 1.4)$ & 91.8 & $( \pm 0.3)$ & -1.8 & $( \pm 0.1)$ & 154.4 & $( \pm 0.2)$ & 35.9 & $( \pm 0.1)$ & 169.4 & $( \pm 0.2)$ \\
\hline & 50 & 0.8 & $( \pm 0.0)$ & 65.8 & $( \pm 0.1)$ & - & - & - & - & -0.8 & $( \pm 0.1)$ & 156.0 & $( \pm 0.0)$ & 34.8 & $( \pm 0.9)$ & 169.2 & $( \pm 0.1)$ \\
\hline & 100 & 0.8 & $( \pm 0.1)$ & - & - & - & - & - & - & -0.9 & $( \pm 0.3)$ & 157.2 & $( \pm 0.5)$ & 35.9 & $( \pm 2.3)$ & 169.5 & $( \pm 0.1)$ \\
\hline \multirow{4}{*}{ PLA10C } & o & 6.2 & $( \pm 0.1)$ & 62.8 & $( \pm 0.2)$ & -21.7 & $( \pm 0.5)$ & 98.9 & $( \pm 0.5)$ & - & - & - & - & 35.5 & $( \pm 1.3)$ & 166.9 & $( \pm 0.3)$ \\
\hline & 25 & 1.3 & $( \pm 0.4)$ & 60.5 & $( \pm 0.1)$ & -3.7 & $( \pm 1.5)$ & 89.7 & $( \pm 0.1)$ & - & - & - & - & 36.3 & $( \pm 0.7)$ & 167.1 & $( \pm 0.1)$ \\
\hline & 50 & 0.7 & $( \pm 0.1)$ & 60.4 & $( \pm 0.5)$ & - & - & - & - & - & - & - & - & 35.5 & $( \pm 3.6)$ & 167.1 & $( \pm 0.0)$ \\
\hline & 100 & 0.5 & $( \pm 0.1)$ & - & - & - & - & - & - & - & - & - & - & 38.2 & $( \pm 0.8)$ & 167.9 & $( \pm 0.3)$ \\
\hline \multirow{4}{*}{ PLA20 } & 0 & 4.2 & $( \pm 0.3)$ & 67.2 & $( \pm 0.1)$ & -15.8 & $( \pm 0.6)$ & 96.3 & $( \pm 0.1)$ & -2.0 & $( \pm 0.3)$ & 154.1 & $( \pm 0.3)$ & 33.4 & $( \pm 0.9)$ & 168.9 & $( \pm 0.1)$ \\
\hline & 25 & 0.9 & $( \pm 0.1)$ & 65.3 & $( \pm 0.1)$ & - & - & - & - & -0.6 & $( \pm 0.1)$ & 156.1 & $( \pm 0.1)$ & 30.0 & $( \pm 1.1)$ & 169.2 & $( \pm 0.1)$ \\
\hline & 50 & 0.6 & $( \pm 0.1)$ & 66.0 & $( \pm 0.1)$ & - & - & - & - & -0.9 & $( \pm 0.1)$ & 155.8 & $( \pm 0.2)$ & 31.3 & $( \pm 0.7)$ & 169.1 & $( \pm 0.3)$ \\
\hline & 100 & 0.3 & $( \pm 0.0)$ & - & - & - & - & - & - & -0.6 & $( \pm 0.1)$ & 156.6 & $( \pm 0.1)$ & 32.6 & $( \pm 0.8)$ & 169.4 & $( \pm 0.1)$ \\
\hline \multirow{4}{*}{ PLA20C } & $\mathbf{0}$ & 2.1 & $( \pm 0.5)$ & 67.7 & $( \pm 0.2)$ & -6.5 & $( \pm 0.4)$ & 95.3 & $( \pm 0.1)$ & -1.5 & $( \pm 0.1)$ & 154.2 & $( \pm 0.1)$ & 27.8 & $( \pm 0.4)$ & 169.2 & $( \pm 0.1)$ \\
\hline & 25 & 0.8 & $( \pm 0.2)$ & 62.1 & $( \pm 0.7)$ & - & - & - & - & - & - & - & - & 32.5 & $( \pm 0.8)$ & 168.4 & $( \pm 0.5)$ \\
\hline & 50 & 1.1 & $( \pm 0.1)$ & 64.6 & $( \pm 0.1)$ & - & - & - & - & - & - & - & - & 34.1 & $( \pm 1.2)$ & 167.8 & $( \pm 0.2)$ \\
\hline & 100 & 0.2 & $( \pm 0.1)$ & - & - & - & - & - & - & - & - & - & - & 32.4 & $( \pm 1.2)$ & 168.2 & $( \pm 0.3)$ \\
\hline \multirow{4}{*}{ PLA30 } & 0 & 2.5 & $( \pm 0.4)$ & 67.6 & $( \pm 0.1)$ & -6.5 & $( \pm 2.9)$ & 95.3 & $( \pm 0.8)$ & -1.5 & $( \pm 0.3)$ & 154.2 & $( \pm 0.2)$ & 27.8 & $( \pm 1.3)$ & 169.2 & $( \pm 0.2)$ \\
\hline & 25 & 0.6 & $( \pm 0.1)$ & 65.3 & $( \pm 0.4)$ & - & - & - & - & -0.5 & $( \pm 0.1)$ & 155.0 & $( \pm 0.2)$ & 27.9 & $( \pm 2.4)$ & 169.0 & $( \pm 0.1)$ \\
\hline & 50 & 0.6 & $( \pm 0.1)$ & 66.0 & $( \pm 0.3)$ & - & - & - & - & -0.6 & $( \pm 0.1)$ & 156.6 & $( \pm 0.5)$ & 34.4 & $( \pm 0.3)$ & 169.6 & $( \pm 0.9)$ \\
\hline & 100 & 0.3 & $( \pm 0.1)$ & - & - & - & - & - & - & -0.8 & $( \pm 0.1)$ & 156.8 & $( \pm 0.1)$ & 36.8 & $( \pm 1.2)$ & 169.4 & $( \pm 0.1)$ \\
\hline \multirow{4}{*}{ PLA30C } & $\mathbf{0}$ & 3.2 & $( \pm 0.0)$ & 65.6 & $( \pm 0.5)$ & -9.8 & $( \pm 0.2)$ & 93.3 & $( \pm 0.7)$ & -1.0 & $( \pm 0.1)$ & 152.8 & $( \pm 0.4)$ & 29.3 & $( \pm 0.3)$ & 168.1 & $( \pm 0.4)$ \\
\hline & 25 & 0.8 & $( \pm 0.1)$ & 62.9 & $( \pm 0.5)$ & - & - & - & - & - & - & - & - & 28.8 & $( \pm 0.1)$ & 167.7 & $( \pm 0.7)$ \\
\hline & 50 & 0.5 & $( \pm 0.1)$ & 65.6 & $( \pm 0.2)$ & - & - & - & - & -0.3 & $( \pm 0.2)$ & 154.0 & $( \pm 0.4)$ & 27.5 & $( \pm 1.5)$ & 168.1 & $( \pm 0.4)$ \\
\hline & 100 & 0.3 & $( \pm 0.1)$ & - & - & - & - & - & - & - & - & - & - & 30.8 & $( \pm 0.5)$ & 168.6 & $( \pm 0.1)$ \\
\hline
\end{tabular}




\section{Conclusions}

The influence of fibre in PLA matrix along with the incorporation of coupling agent provoked a chain scission phenomenon during processing. A reduction in the number-average molecular weight and an increase in polydispersity index were shown. Moreover, a diminution of the cold crystallization temperature in composites suggested shorter polymer chains. All that effects together with the nucleating ability of fibre, contributed to higher crystallinity in all biocomposites.

The application of normalized water absorption experiments was useful to simulate and monitor the degradation induced by accelerated hydrothermal treatment on PLA/sisal biocomposites. Along the hydrothermal ageing treatment, the behaviour of the PLA/sisal biocomposites can be sequenced as follows:

i. Swelling took place for all materials and temperatures. Water saturation mass increased for composites due to the incorporation of fibre, which generated more penetration paths. Temperature enhanced water saturation phenomenon, showed by shorter saturation times and higher diffusion coefficients.

ii. Surface was weakened caused by differential swelling between fibre and matrix. As observed by electron microscopy, a cracking effect occurred, promoting capillarity and transport of water moieties.

iii. Chain scission phenomenon was revealed by a decrease in the molecular weight of polylactide matrix and a wider molecular weight distribution was observed.

iv. Crystal formation was developed, as showed the increment of crystallinity index. Due to the hydrolysis, along with the effect of temperature, a fast movement followed by a restructuration of the polymer chains occurred, favoured by nucleating ability of sisal fibres.

v. Hindrance of water absorption occurred in all materials. For composites, it was higher when sisal fibre increased. A reduction of the diffusion coefficient was shown, suggesting that crystal formation acted as a barrier and hindered the advance of penetrant.

vi. The addition of coupling agent showed slightly different influence depending on the composition and hydrothermal ageing temperature. An inflection point around $20 \%$ of sisal fibre was found for the tendency of some parameters $\left(M_{S}, D\right.$ and $\left.X_{C}\right)$. This difference was more visible for ageing temperatures below than above the glass transition.

\section{Acknowledgements}

The authors would like to acknowledge the Spanish Ministry of Economy and Competitiveness, through the Research Project ENE2011-28735-C02-01. Generalitat Valenciana is thanked for the APOSTD/2013/054, and ACOMP/2013/143 programs. The Vice-Rectorate for Research of Universitat Politècnica de València is thanked for additional support through the PAID-06SP20120581 project. Universitat Politècnica de València is also thanked for the concession of a pre-doctoral grant to Óscar Gil Castell. 
O. Gil-Castell, J. D. Badia, T. Kittikorn, E. Strömberg, A. Martínez-Felipe, M. Ek, S. Karlsson, A. Ribes-Greus.

Hydrothermal ageing of polylactide/sisal biocomposites. Studies of water absorption behavior and physicochemical performance. Polymer Degradation and Stability 2014; 108, 212-222

\section{References}

[1] Mapleston P. Environmentally degrading: Bioplastics in Europe (part 2). Plastics Engineering Europe Spring, pg. 24-29, 2006.

[2] Mapleston P. Following the green line: Bioplastics in Europe. Plastics Engineering Europe Winter, pg. 14-19, 2005.

[3] Benjamin B, Mussig J. Impact and tensile properties of PLA/Cordenka and PLA/flax composites. Composites Science and Technology, 2008; 68:1601-7

[4] Oksman K, Skrifvars M, Selin JF. Natural fibres as reinforcement in polylactic acid (PLA) composites. Composites Science Technology, 2003; 63:1317-24.

[5] Yew GH, Mohd Yusof AM, Mohd Ishak ZA, et al. Water absorption and enzymatic degradation of poly(lactic acid)/rice starch composites. Polymer Degradation and Stability, 2005; 90:488-500.

[6] Huda MS, Drzal LT, Mohanty AK, et al. Chopped glass and recycled newspaper as reinforcement fibres in injection molded poly(lactic acid) (PLA) composites: a comparative study. Composites Science and Technology, 2006; 66:1813-24.

[7] Hu RH, Lim JK. Fabrication and mechanical properties of completely biodegradable hemp fibre reinforced PLA composites. Journal of Composite Materials, 2007; 41:1655-69.

[8] Masud SH, Lawrence TD, Manjusri M. A study on biocomposites from recycled newspaper fibre and poly(lactic acid). Industrial and Engineering Chemical Research, 2005; 44:5593-5601.

[9] Smita M, Sushil KV, Sanjay KN. Dynamic mechanical and thermal properties of MAPE treated jute/HDPE composites. Composites Science and Technology, 2006; 66:538-547.

[10] Corrales F, Vilaseca F, Llop M, Giromes J, Mendez JA, Mutje P. Chemical modification of jute fibres for the production of green-composites. Journal of Hazardous Materials, 2007; 44:730-735.

[11] Ray D, Sarkar BK, Rana AK, Bose N. The mechanical properties of vinyl ester resin matrix composites reinforced with alkali-treated jute fibres. Composites: Part A, 2001; 32:119-127.

[12] Stark N. Influence of moisture absorption on mechanical properties of wood flour-polypropylene composites. Journal of Thermoplastic Composite Materials, 2001; 14:421-32.

[13] Marcovich NE, Reboredo MM, Aranguren MI. Dependence of the mechanical properties of wood flourpolymer composites on the moisture content. Journal of Applied Science, 1998; 68:2069-76.

[14] Rangaraj SV, Smith L. Effects of moisture on the durability of a wood/thermoplastic composite. Journal of Thermoplastic Composite Materials, 2000; 13(3):140-61.

[15] Dhakal HN, Zhang ZY, Richardson MOW. Effect of water absorption on the mechanical properties of hemp fibre reinforced unsaturated polyester composites. Composites Science and Technology, 2007; 67(7-8):167483.

[16] Le Duigou A, Davies P, Baley C. Interfacial bonding of Flax fibre/Poly(L-lactide) bio-composites. Composites Science and Technology, 2010; 70:231-239

[17] RH Hu, M Sun, JK Lim. Moisture absorption, tensile strength and microstructure evolution of short jute fiber/polylactide composite in hygrothermal environment. Materials and Design, 2010; 31:3167-3173

[18] HS Kim, HJ Kim. Enhanced hydrolysis resistance of biodegradable polymers and bio-composites. Polymer Degradation and Stability, 2008; 93:1544-1553.

[19] Le Duigou A, Davies P, Baley C. Seawater ageing of flax/poly(lactic acid) biocomposites. Polymer Degradation and Stability, 2009; 94:1151-1162.

[20] Quan H, Li Z, Yang M, Huang R. On transcrystallinity in semi-crystalline polymer composites. Composites Science and Technology, 2005; 65(7-8):999-1021.

[21] Lu JZ, Wu Q, McNann HS. Chemical coupling in wood fiber and polymer composites: a review of coupling substances and treatment. Wood and Fiber Science, 2000; 32(1):88-104.

[22] Nabi Saheb D, Jog JP. Natural fiber polymer composites: a review. Advanced Polymer Technology, 1999; 18(4):351-63.

[23] Rozman HD, Lee MH, Kumar RN, Abusanag A, Mohd Ishak ZA. The effect of chemical modification of rice husk with glycidyl methacrylate on the mechanical and physical properties of rice husk-polystyrene composites. Journal of Wood Chemistry and Technology, 2000; 20(1):93-109.

[24] Gaylord NG, Mehta R. Peroxide-catalyzed grafting of maleic anhydride onto molten polyethylene in the presence of polar organic compounds, Journal of Polymer Science Part A: Polymer Chemistry, 1998; 
O. Gil-Castell, J. D. Badia, T. Kittikorn, E. Strömberg, A. Martínez-Felipe, M. Ek, S. Karlsson, A. Ribes-Greus.

Hydrothermal ageing of polylactide/sisal biocomposites. Studies of water absorption behavior and physicochemical performance. Polymer Degradation and Stability 2014; 108, 212-222

\section{6:1189-1198.}

[25] Kim SJ, Shin BS, Hong JL, Cho WJ, Ha CS. Reactive compatibilization of the PBT/EVA blend by maleic anhydride. Polymer, 2001; 42:4073-4080.

[26] Raquez JM, Narayan R, Dubois P. Recent Advances in reactive extrusion processing of biodegradable polymer-based compositions. Macromolecular Materials and Engineering, 2008; 293:447-470.

[27] Berthé V, Ferry L, Bénéze t JC, Bergeret A. Ageing of different biodegradable polyesters blends mechanical and hygrothermal behavior. Polymer Degradation and Stability, 2010; 95:262-9.

[28] Beg MDH, Pickering KL. Accelerated weathering of unbleached and bleached kraft wood fibre reinforced polypropylene composites. Polymer Degradation and Stability, 2008; 93:1939-46.

[29] Badia JD, et al., Water absorption and hydrothermal performance of PHBV/sisal biocomposites, Polymer Degradation and Stability (2014), http://dx.doi.org/10.1016/j.polymdegradstab.2014.04.012

[30] Kale G, Auras R, Singh S P. Degradation of commercial biodegradable packages under real composting and ambient exposure conditions. Journal of Polymer and Environments, 2006; 14:317-334.

[31] Kale G, Auras R, Singh SP, Narayan R. Biodegradability of polylactide bottles in real and simulated composting conditions. Polymer Testing, 2007; 26:1049-1061.

[32] Badia JD, Santonja-Blasco L, Martínez-Felipe A, Ribes-Greus A. Hygrothermal ageing of reprocessed polylactide. Polymer Degradation and Stability, 2012; 97:1881-1890.

[33] Kittikorn T. Tuning the long-term properties to control biodegradationby surface modifications of agricultural fibres in biocomposites. ISBN:978-91-7501-677-1. Ph.D. Thesis. Kungliga Tekniska Högskolan, 2013.

[34] Hwang SW, Lee SB, Lee CK, Lee JY, Shim JK, Selke SEM, Soto-Valdez H, Matuana L, Rubino M, Auras R. Grafting of maleic anhydride on poly(L-lactic acid). Effects on physical and mechanical properties. Polymer Testing, 2012; 31:333-344.

[35] ISO 62. Plastics. Determination of water absorption; 2008.

[36] ISO 291. Plastics. Standard atmospheres for conditioning and testing; 1997.

[37] Badía JD, Strömberg E, Karlsson S, Ribes-Greus A. Material valorisation of amorphous polylactide. Influence of thermo-mechanical degradation on the morphology, segmental dynamics, thermal and mechanical performance. Polymer Degradation and Stability, 2012; 97:670-8.

[38] Neogi P. Diffusion in polymers, Marcel Dekker, New York, 1996.

[39] Fairbridge C, Ross RA, Sood SP. A kinetic and surface study of the thermal decomposition of cellulose powder in inert and oxidizing atmospheres. Journal of Applied Polymer Science, 1978; 22(2):497-510.

[40] Fischer EW, Sterzel HJ, Wegner G. Investigation of structure of solution grown crystals of lactide copolymers by means of chemical-reactions. Kolloid and Polymer Science, 1973; 251(11):980-90.

[41] Ndazi BS, Karlsson S. Characterization of hydrolytic degradation of polylactic acid/rice hulls composites in water at different temperatures. eXPRESS Polymer Letters, 2011; 5(2):119-131.

[42] Yew GH, MohdYusof AM, MohdIshak ZA, Ishiaku US. Water absorption and enzymatic degradation of poly(lactic acid)/rice starch composites. Polymer Degradation and Stability, 2005; 90:488-500.

[43] Wang H, Sun XZ, Seib P. Strengthening blends of poly(lactic acid) and starch with methylene diphenyl diisocyanate. Journal of Applied Polymer Science, 2001; 82:1761-7.

[44] Bismarck A, Askargorta IA, Springer J, Lampke T, Wielage B, Stamboulis A. Surface characterization of flax, hemp and cellulose fibres, surface properties and the water uptake behaviour. Polymer Composites, 2002; 23:872-94.

[45] Neogi P. Diffusion in polymers, Marcel Dekker, New York, 1996.

[46] Tang CY, Chen DZ, Yue TM, Chan KC, Tsui CP, Peter HF. Water absorption and solubility of PHBHV/HA nanocomposites. Compos Science and Technology, 2008; 68:1927-1934.

[47] Bellenger V,Ganemt M, Mortaigne B, Verdu J. Lifetime prediction in the hydrolytic ageing of polyesters. Polymer Degradation and Stability, 1995; 49:91-97.

[48] George J, Bhagawan SS, Thomas S. Effects of environment on the properties of low-density polyethylene composites reinforced with pineapple-leaf fibre. Composites Science and Technology, 1998; 58:1471-85.

[49] Chow CPL, Xing XS, Li RKY. Moisture absorption studies of sisal fibre reinforced polypropylene composites. Composites Science and Technology, 2007; 67(2):306-13.

[50] Dhakal HN, Zhang ZY, Richardson MOW. Effect of water absorption on the mechanical properties of hemp 
O. Gil-Castell, J. D. Badia, T. Kittikorn, E. Strömberg, A. Martínez-Felipe, M. Ek, S. Karlsson, A. Ribes-Greus.

Hydrothermal ageing of polylactide/sisal biocomposites. Studies of water absorption behavior and physicochemical performance. Polymer Degradation and Stability 2014; 108, 212-222

fibre reinforced unsaturated polyester composites. Composites Science and Technology, 2007; 67(7-8):167483.

[51] Thwe MM, Liao K. Durability of bamboo-glass fiber reinforced polymer matrix hybrid composites. Composites Science and Technology, 2003; 63(3-4):375-87.

[52] Shah S, Zhu K, Pitt C. Poly-DL-lactic acid: polyethylene glycol block copolymers. The influence of polyethylene glycol on the degradation of poly-DL-lactic acid. Journal of Biomaterials Science Polymer Edition, 1994; 5(5):421-31.

[53] Foulc MP, Bergeret A, Ferry L, Ienny P, Crespy A. Study of hygrothermal ageing of glass fibre reinforced PET composites. Polymer Degradation and Stability, 2005; 89(3):461-70. 
O. Gil-Castell, J. D. Badia, T. Kittikorn, E. Strömberg, A. Martínez-Felipe, M. Ek, S. Karlsson, A. Ribes-Greus. Hydrothermal ageing of polylactide/sisal biocomposites. Studies of water absorption behavior and physicochemical performance. Polymer Degradation and Stability 2014; 108, 212-222

\section{ANNEX. OPEN-ACCESS POLICIES}

\section{One journal found when searched for: $\mathbf{0 1 4 1 - 3 9 1 0}$}

Joumal: Polymer Degradation and Stability (ISSN: 0141-3910)

RoMEO: This is a RoMEO green journal

Paid OA: A paid open access option is available for this journal.

Author's Pre-print: $\checkmark$ author can archive pre-print (ie pre-refereeing

Author's Post-print: $\checkmark$ author can archive post-print (ie final draft post-refereeing)

Publisher's Version/PDF: $\mathbf{X}$ author cannot archive publisher's version/PDF

General Conditions:

Pre-print allowed on any website or open access repository
Voluntary deposit by auther of authors post-print allowed on authors' personal website, arXiv. org or institutions open scholarly website including Institutional Repository, without embargo, where

there is not a policy or mandate
Deposit due to Funding Body, Institutional and Governmental policy or mandate only allowed where separate agreement between repository and the publisher exists. Permitted deposit due to Funding Body, Institutional and Governmental policy or mandate, may be required to comply with embargo periods of 12 months to 48 months

Set statement to accompany deposit

Published source must be acknowledged

Publisher's version/PDF cannot be used

Articles in some journals can be made Open Access on payment of additional charge

Mandated OA: Compliance data is available for $\underline{57 \text { funders }}$

Paid Open Access: $\underline{\text { Open Access Articles }}$

Notes:

- Publisher last contacted on 18/10/2013

Copyright: Article Postina Policies - Rights \& responsibilities - Eunding Body Aareements - Green Open Access - Open Access License Policy Green Open Access - Elsevier Journal Specific Embargo Periods

Updated: 16-May-2014- Suggest an update for this record

Link to this page: $h$ htp://hww.sherpa ac.ukromeo/issn/0141-3910 